\begin{tabular}{|c|c|c|c|}
\hline Eiszeitalter u. Gegenwart & $\mathbf{4 6}$ & $\begin{array}{c}99-119 \\
21 \mathrm{Abb} .\end{array}$ & Hannover 1996 \\
\hline
\end{tabular}

\title{
Über glaziale Erosion und Übertiefung
}

\author{
Karl Albert HabBE*)
}

Glacial erosion and overdeepening, motion mechanism of advancing glaciers, meltwater movement in, below and along glaciers, Sulzenau glacier (Stubai Alps, Tyrol), Iller foreland glacier (German Alpine Foreland), Vatnajökull outlet glaciers (Iceland), Western Rhein foreland glacier (German Alpine Foreland)

Kurzfassung: Glaziale Erosion und Übertiefung ist - wie die Längsprofile aller glazial geformten Täler zeigen - kein über die gesamte Längserstreckung des Gletschers gleichmäßig wirksamer Vorgang, sondern durch ausgeprägte Diskontinuitäten gekennzeichnet. Die Gründe dafür sind früh diskutiert, das Problem ist jedoch nie gelöst worden. Der Erklärungsansatz von H. Lous (1952) hatte aber bereits deutlich gemacht, daß es nur geklärt werden kann, wenn man den zugrunde liegenden Bewegungsmechanismus der Gletscher kennt. Es wird anhand von Beobachtungen aus dem Gebiet des letztkaltzeitlichen Illergletschers gezeigt, daß kaltzeitliche Gletscher mit positivem Massenhaushalt (vorstoßende Gletscher) sich anders bewegt haben müssen als heutige Gletscher, die zumeist einen negativen Massenhaushalt haben (d. h. zurückschmelzen). Es wird ferner gezeigt, daß dieser Bewegungsvorgang an vorstoßenden Fußgletschern des Vatnajökull in Island auch heute noch beobachtet werden kann. Er ist gekennzeichnet durch eine Summation zahlreicher, relativ kurzdauernder und nur relativ kleine Distanzen überbrückender Vorschübe flacher Eisschilde auf Scherflächen über stagnierendem Eis vorhergehender Vorstöße, die ausgelöst wurden durch niederschlagsbedingte Massenüberschüsse im Nährgebiet. Ein solcher Bewegungsvorgang impliziert, daß eine Einwirkung des Gletschers auf den Untergrund nur dort (und dann) möglich ist, wo (und wenn) der Gletscher über seine stagnant-ice-Unterlage vorstößt, d. h. nur im Bereich unmittelbar hinter der Gletscherstirn. Größere Erosionsbeträge sind nur dann zu erwarten, wenn der Gletscher nach dem Vorstoß längere Zeit in der erreichten Maximalposition verharrt und zusätzlich unter hydrostatischem Druck stehendes (Schnee-)Schmelzwasser auf den Untergrund einwirkt. Zur Schmelzwasserbewegung im Gletscher werden weitere Beobachtungen aus Island beigebracht, zur Schmelzwasserwirkung auf den Untergrund Beobachtungen (vorwiegend) aus dem deutschen Alpenvorland. Insgesamt ergibt sich, daß die Diskontinuitäten glazialer Erosion und Übertiefung sich erklären lassen durch den beschriebenen Bewegungsmechanismus vorstoßender Gletscher, die Schutzwirkung überfahrenen stagnierenden Eises vorhergehender Vorstöße und die Eigenart der (Schnee-)Schmelzwasserbewegung in, unter und am Rande des Gletschers. Weil die beschriebenen Prozesse in erster Linie unmittelbar hinter der Stirn des vorstoßenden Gletschers ablaufen, sind sie ein räumlich und zeitlich beschränktes Phänomen, müssen gerade deswegen aber von außerordentlicher Intensität sein.

*) Anschrift des Verfassers:

Prof. Dr. K. A. HaBBe, Institut für Geographie der Universität Erlangen-Nürnberg, Kochstr. 4, 91054 Erlangen.

\section{[On glacial erosion and overdeepening]}

Abstract: Glacial erosion and overdeepening is - as can be shown by the longitudinal profile of every valley formed by glaciers - not a process active on the whole longitudinal extension of the glacier in the same way, but is characterized by marked discontinuities. The reasons have been discussed for nearly a century, but the problem remained unsolved until now. It can - as H. Louis (1952) has demonstrated - be solved only when the motion mechanism of the glaciers is known. The present paper demonstrates on the base of observations in the area of the Iller glacier of the last glaciation that Pleniglacial glaciers with positive mass budget (advancing glaciers) have moved in another way than present-day glaciers with their - mostly - negative mass budget. Furthermore it is demonstrated that this particular motion mechanism can actually be observed at advancing outlet glaciers of the Vatnajökull in Iceland. It is characterized by a summation of numerous push movements of flat ice-shields on shear-planes over stagnant-ice of preceding advances, all of them of relatively short duration and range. They originated in precipitation-caused mass surpluses in the feeding area. This motion mechanism implies that an impact on the underground is possible only where (and when) the glacier advances beyond its stagnant-ice basement, i. e. immediately behind the front of the advancing glacier. A larger amount of glacial erosion can be expected only when the glacier after the advance remained in the maximum position reached for a longer time and, additionally, (snow)meltwater under hydrostatic pressure could affect the underground. Further observations on meltwater movement within the glacier are presented from Iceland, on meltwater impact on the underground (mainly) from the German Alpine Foreland. To sum up, the discontinuities of glacial erosion and overdeepening can be explained by the motion mechanism of advancing glaciers described, the protective effect of the overridden stagnant-ice basement of preceding advances, and the characteristic movement of (snow)meltwater in, below and along the glacier. Because the erosion processes described take place (mainly) immediately behind the front of the advancing glacier, they are a phenomenon restricted in space as well as in time, but therefore must be of extraordinary intensity

\section{Das Grundproblem}

Wie glaziale Erosion vor sich geht, ist teils seit über einhundert Jahren bekannt, teils bis heute ungeklärt und daher umstritten.

Bekannt ist aus Beobachtungen in heutigen Gletschervorfeldern, die von den Gletschern erst im $\mathrm{Zu}$ - 




Abb. 1: Spuren schrammender („Detersion“) und aushebender („Detraktion“) glazialer Erosion im Vorfeld des Sulzenauferners (Stubaier Alpen, Tirol). Der Aufnahmepunkt lag in $2350 \mathrm{~m}$ Höhe auf einer Felsschwelle nur wenige hundert Meter vor dem Gletscherende (Aufn. Verf. 4.8.1990)

Fig. 1: Traces of glacial smoothing (Detersion) and plucking (Detraction) in the forefield of the Sulzenauferner (Stubai Alps, Tyrol). The photograph has been taken in $2350 \mathrm{~m}$ a.s.I. on a rock sill a few hundred metres before the glacier front (phot. K.A.H. 4.8.1990).

ge ihres säkularen Rückschmelzens seit dem letzten Hochstand um 1850 geräumt wurden, daß die Abtragung teils schleifend („Detersion“), teils größere Blöcke an Klüften ablösend und aushebend („Detraktion") vor sich gehen kann (Abb. 1). Durch das Zusammenwirken beider Vorgänge kann es zur Ausbildung von Rundhöckern kommen (CAROL 1943, 1947).

Aber beide Vorgänge sind nur dort beobachtbar, wo das glazialerosiv beanspruchte Gestein an der Geländeoberfläche ansteht, an Engstellen also und - vor allem - auf Felsschwellen, also gerade dort, wo die Abtragung - langfristig (d. h. über die gesamte Zeit der Eisbedeckung hinweg) gesehen - am wenigsten wirksam war. Und es ist durchaus offen, wann diese so offensichtlichen Spuren glazialer Erosion entstanden sind, ob sie also ein Zeugnis kontinuierlicher Abtragung oder eines nur zeitweise wirksamen Prozesses sind. Das erstere ist - wegen des offensichtlich geringen Wirkungsgrades - eher unwahrscheinlich, jedenfalls dann, wenn, was häufig der Fall ist, Unterschiede in der Gesteinshärte als zusätzlich wirksame Ursache ausscheiden. Nimmt man dagegen das zweite an, stellt sich die Frage, welche nur zeitweilig wirksamen Umstände die nur geringe Erosionswirkung der Gletscher gerade an den Stellen bewirkt haben, wo sie am besten zu beobachten sind. Das Problem wird noch deutlicher, wenn man die in den Talweitungen zwischen den Felsschwellen gelegenen übertieften - und meist durch junge (glaziale, glazifluviale, glazilimnische) Sedimente verfüllten - Becken (Abb. 2) in die Betrachtung einbezieht, wo die glaziale Erosion offenbar wesentlich kräftiger wirksam war. Sie belegen, daß es im Längsprofil eines glazial geformten Tales einen Wechsel gibt zwischen Bereichen sehr kräftiger und ausgeprägt retardierter Erosion. Vergegenwärtigt man sich schließlich, daß der Wechsel von Becken und Schwellen nicht nur die wasser-(und eis-)scheidennahen Bereiche des Hochgebirges betrifft, sondern sich über ein gestuftes Längsprofil (Abb. 3 und 4) in die inneralpinen Talgründe und unter deren Sedimentfüllung ${ }^{1}$ ) bis ins Alpenvorland fortsetzt (Abb. 5), dann wird klar, daß glaziale Erosion (und Übertiefung) jedenfalls kein über die gesamte Länge der pleistozänen Gletschererstreckung gleichmäßig wirksamer Vorgang, sondern durch ausgeprägte Diskontinuitäten charakterisiert war. Was sie bewirkte, ist bis heute offen.

\section{Der Erklärungsansatz von H. LouIs}

Das Problem ist zwar früh gesehen und zeitweise heftig diskutiert worden ${ }^{2}$ ), aber eine Durchsicht der

\footnotetext{
1) Ein typisches - und gut erforschtes - Beispiel dafür ist das inneralpine Isartal (BADER 1979, Frank 1979, vgl. dazu FisChER 1994).

2) Berühmt wurde die Auseinandersetzung darüber zwischen A.Heim $(1885,1919)$ und A. Penck $(1899,1912$, Penck \& Brückner 1901-09). Vgl. dazu im übrigen Lous (1952)
} 


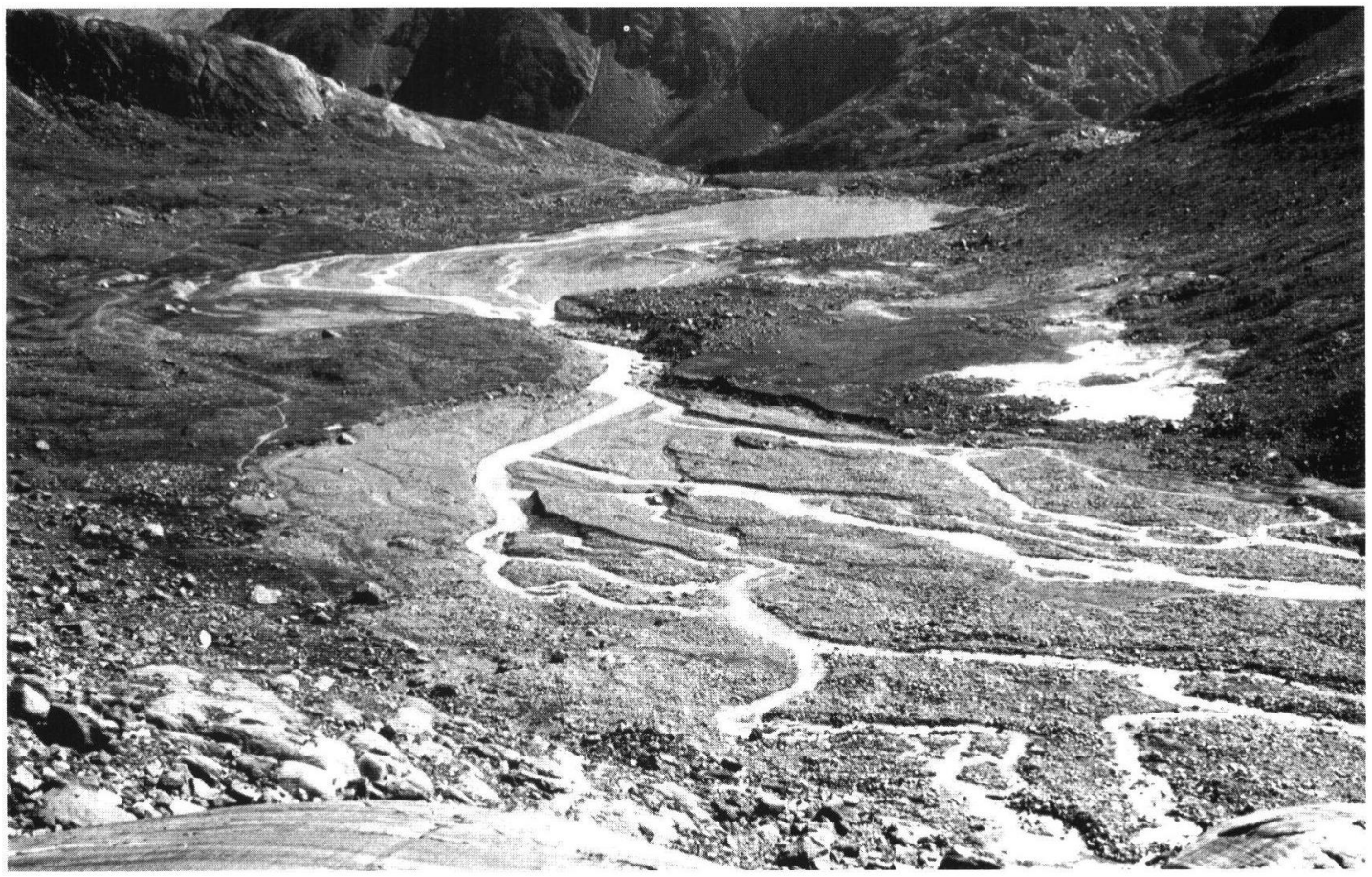

Abb. 2: Das vom Gletscher seit dem Hochstand von 1850 geräumte übertiefte Becken des Sulzenauferners oberhalb der Sulzenau-Hütte. Der 1850 er Gletscher reichte bis an die Felsschwelle im Hintergrund, die Moräne im Mittelgrund mit dem Bachdurchbruch stammt von 1920. Aufnahme talab vom gleichen Punkt wie Abb. 1 (Aufn. Verf. 4.8.1990).

Fig. 2: The overdeepened basin of the Sulzenauferner above the Sulzenau refuge. The glacier of the 1850 readvance extended to the rock sill in the background, the terminal moraine in the centre with the brook cut is from the 1920s. Photograph taken downvalley from the same place as fig, 1 (phot. K.A.H. 4.8.1990).

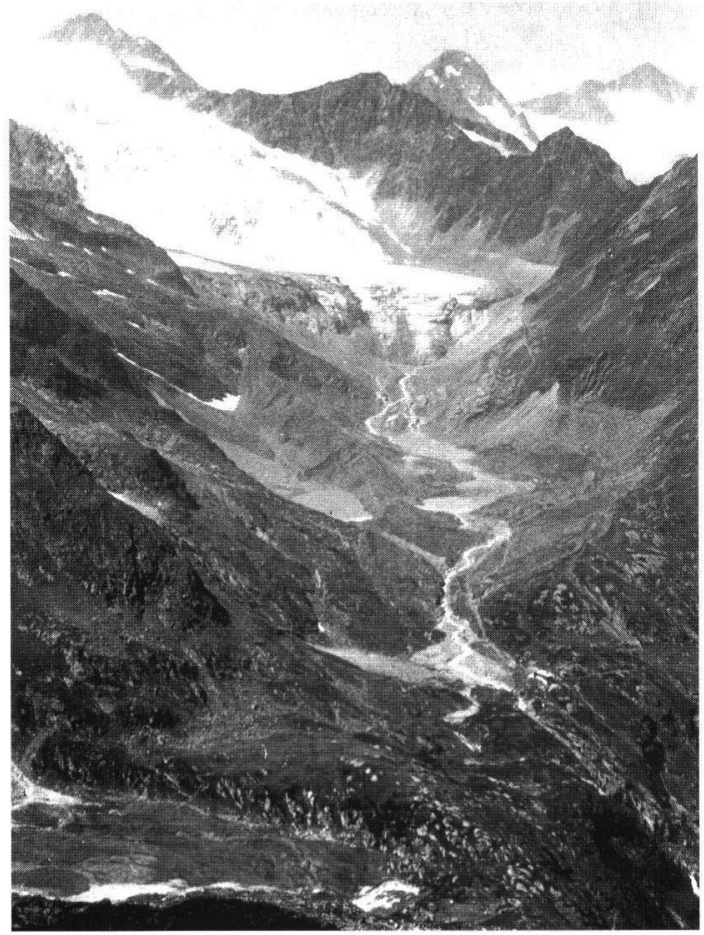

Abb. 3: Das gestufte Längsprofil der SulzenaufernerTalung, stark verkürzt von der Mair-Spitze (2781 m) gesehen. Der Sulzenauferner im Hintergrund erhält auf der Stufe oberhalb der Gletscherstirn einen Zustrom von links aus der Fernerstube. Das Becken oberhalb der Sulzenau-Hütte wird längsgeteilt durch eine große postglaziale Ufermoräne, hinter der links die Blaue Lacke, ein Moränenstausee, erkennbar ist. Unterhalb der Sulzenau-Hütte rechts im Vordergrund der Kopf des Steilabfalls zur Sulzenau-Alm (zur Rahmentopographie vgl. Abb. 4). Zur Zeit des letztglazialen Gletscherhochstandes reichte das Eis aus dem Hintergrund bis fast auf die Höhe des Aufnahmepunktes. Gipfel im Hintergrund (von links): Aperer Pfaff $3351 \mathrm{~m}$, Schaufelspitze 3333 m, Stubaier Wildspitze 3340 m (Aufn. Verf. 2. 8. 1990).

Fig. 3: The flight of steps in the Sulzenauferner valley, seen from the Mair Spitze $(2781 \mathrm{~m})$. The Sulzenauferner in the background gets an affluent from the left - the Fernerstube - on the step above the glacier front. The basin above the Sulzenau refuge is lengthwise divided by a large lateral moraine of postglacial age, on its left a moraine-dammed lake - the Blaue Lacke - is visible. Below the Sulzenau refuge in the right foreground the head of the precipice to the Sulzenau Alm (for the topographic setting see fig. 4). During the glacier maximum of the last glaciation the ice extended from the background to nearly the place from which the photograph was taken. Mountains in the background (from left to right): Aperer Pfaff $3351 \mathrm{~m}$, Schaufelspitze $3333 \mathrm{~m}$. Stubaier Wildspitze $3340 \mathrm{~m}$ (phot. K.A.H. 2.8.1990). 


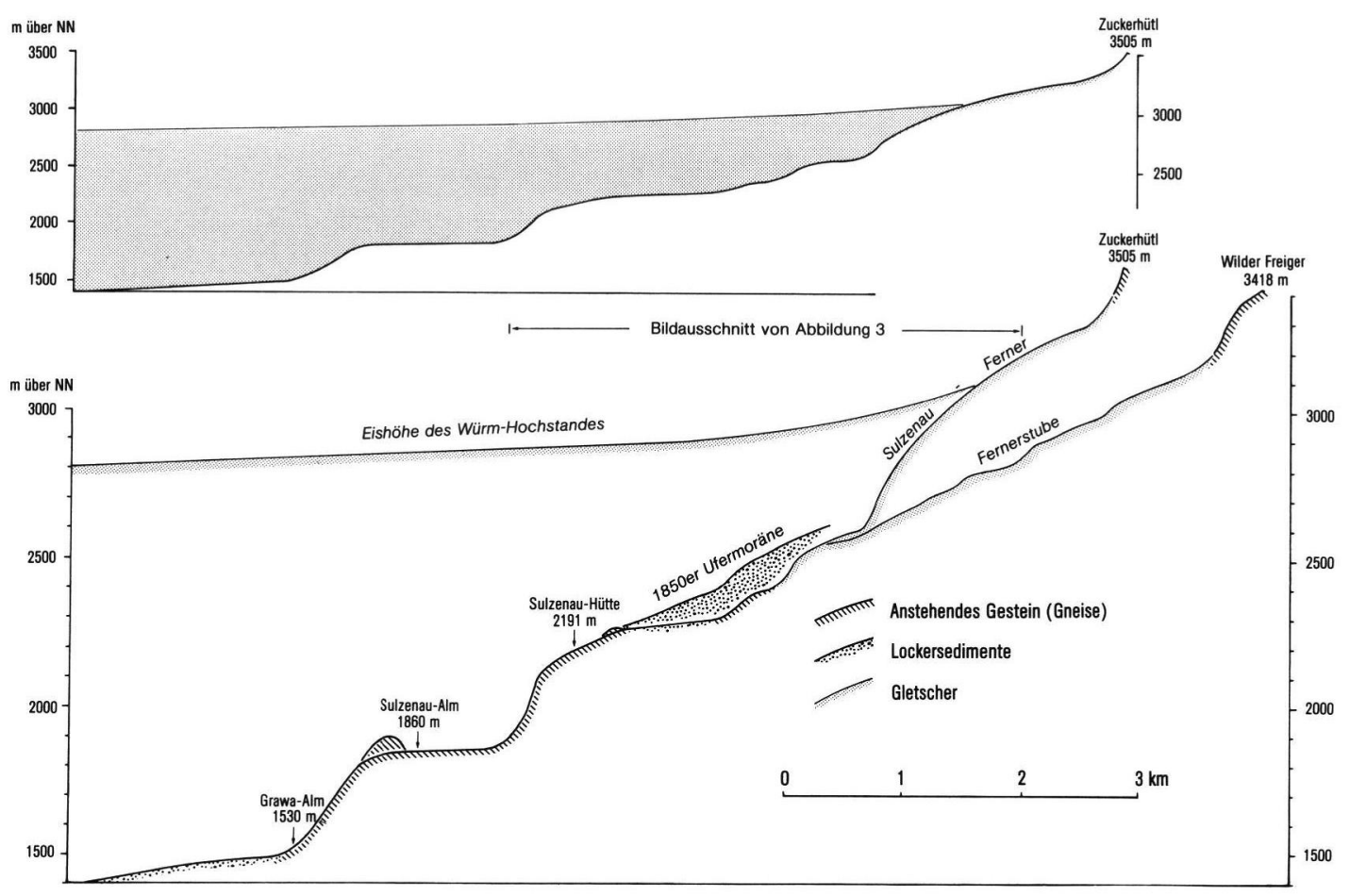

Abb. 4: Längsprofil der Sulzauferner-Talung, 2,5fach überhöht (unten) und nicht überhöht (oben). Obergrenze des Gletschers während des letztkaltzeitlichen Hochstandes in Anlehnung an VAN Husen (1987). Näheres im Text.

Fig. 4: Longitudinal profile of the Sulzenauferner valley. Vertical scale 2,5 x exaggerared (below) and non-exaggerated (above). Upper boundary of the glacier during the Würm maximum after van Husen (1987). For details see text.

einschlägigen neueren Literatur ${ }^{3}$ ) zeigt, daß trotz zahlloser neuer Beobachtungen eine befriedigende Lösung aussteht. Einen der wenigen bis heute bemerkenswerten Versuche, dem Problem beizukommen, hat - in einem der ersten Bände von „Eiszeitalter und Gegenwart" - H. Louss (1952) unternommen. Seine Überlegungen sind seinerzeit in der deutschen Literatur vielfach (wenn auch nicht immer richtig) zitiert worden, haben aber keinen Eingang in die internationale Diskussion gefunden. Später stand auch im deutschen Sprachbereich die Rezeption (vorwiegend) angelsächsischer glaziologischer Arbeiten (zusammenfassend: PATERSON 1969, ${ }^{3}$ 1994) im Vordergrund des Interesses, so daß Lous' Modellvorstellungen kaum mehr Beachtung fanden. Gleichwohl lohnt sich eine Auseinandersetzung damit auch heute noch.

Louss stützte seine Überlegungen auf die von R. FinSTERWALDER $(1931,1950)$ an schnell sich bewegenden Gletschern Hochasiens beobachtete (und benannte) „Blockschollenbewegung“ und benutzte sie zur Erklärung des gestuften Längsprofils glazial geformter hochalpiner Täler (Abb. 6). Vergleicht man Louss' „Kaskaden-Modell“ mit den tatsächlichen

3) Zusammenfassend: Embleton \& King 1975, Sugden \& John 1976 , LOUIS/FisCHER 1979, MARCiNEK 1985, zuletzt MeNZies 1995-96.
Gegebenheiten im eisscheidennahen Bereich heutiger Gletschertäler, so erscheint es auf den ersten Blick durchaus plausibel, auch wenn man nicht die zumeist benutzten überhöhten, sondern nicht-überhöhte Profile zum Vergleich heranzieht (Abb. 4): die Gefällssprünge sind teilweise so kräftig, daß ein Wechsel von Druckentlastung am Kopf, Drucküberlastung am Fuß der Gefällssteilen, wie ihn das Modell unterstellt, als Erklärung für die beobachteten Phänomene denkbar erscheint. Denkbar erscheint darüber hinaus, daß sich aus der Drucküberlastung am Fuß der Gefällssteilen eine Kolkwirkung, also der Ansatz für eine Übertiefung ergab.

Das Kaskaden-Modell erklärt jedoch nur die Verstärkung bereits bestehender Gefällsunterschiede, nicht aber deren Entstehung, und es erklärt auch nicht, weshalb Becken und Schwellen auch noch unter der Lockersedimentfüllung der inneralpinen Täler (also bei nur flachem Längsprofil) und im Gebirgsvorland (bei Gegengefälle der präglazialen Landoberfläche) auftreten. Es reicht daher für die Erklärung glazialer Erosion und Übertiefung sicher nicht aus. Man kann darüber hinaus durchaus bezweifeln, ob überhaupt „Blockschollenbewegung“ unter kaltzeitlichen Verhältnissen so funktioniert haben kann, wie Lous es unterstellte, ob also der wesentliche Grund für die 
$m$
2000
1000
0.1

H Holozäne Seesedimente

Wb Würmzeitliche Seesedimente

W Würmzeitliche Kiese und Moränen

m Moränen und Kiese, würmzeitlich oder älter

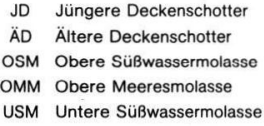

RV Randenverwerfung

BV Buchberg-Verwerfung

Alp Alpenrand-Überschiebung

USM Untere Süßwassermolasse

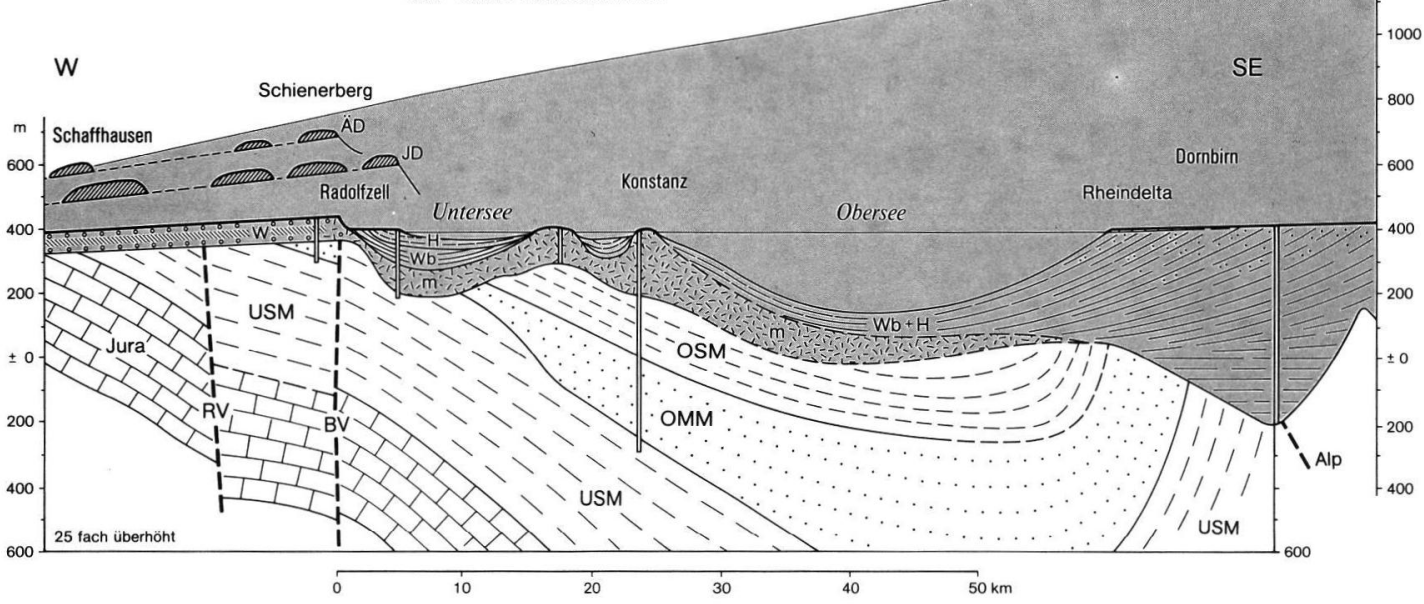

Abb. 5: Längsprofil durch das Bodenseebecken und den letztkaltzeitlichen Rhein-Vorlandgletscher mit 25facher Überhöhung (unten) und - nur für den Gletscher - nicht überhöht (oben). In Anlehnung an SCHREINER (1979), KRAYSS \& KELLER (1983) und Keller (1994). Das obere Profil zeigt, daß der Rheingletscher - wie alle Vorlandgletscher - im Verhältnis zu seiner Flächenausdehnung außerordentlich dünn war, sein Oberflächengefälle gering und auch das zu überwindende Gegengefälle des präquartären Untergrunds nur schwach geneigt.

Fig. 5: Longitudinal profile of the Bodensee basin and the Rhein foreland glacier of the last glaciation. Vertical scale $25 \mathrm{x}$ exaggerated (below) and non-exaggerated (above). After SCHreInER (1979), Krayss \& Keller (1983) and Keller (1994). The upper profile shows that the Rhein glacier - as every foreland glacier - was extremely thin and that its longitudinal gradient and also the counter inclination of the pre-Quaternary underground were very low.

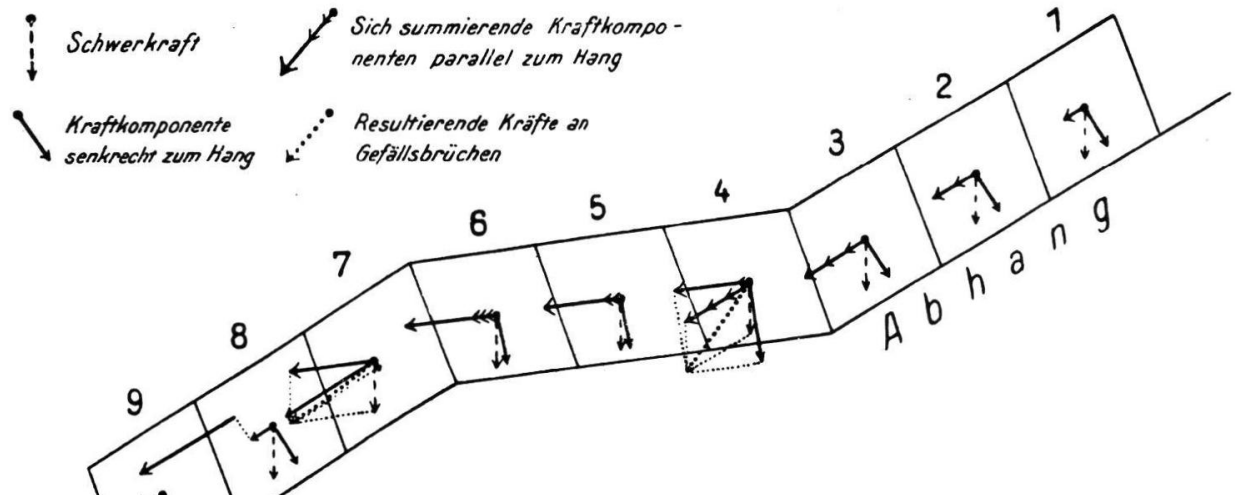

Schema des Bodendrucks eines gedachten Stromes aus starren Einzelkörpern bei wechselndem Bodengefälle. (Beachte insbesondere die Größenunterschiede der „Druckkomponente senkrecht zum Hang" bei Quader 4 und 7 gegenüber den übrigen Quadern; Abb. 1 aus Louis (1952). 


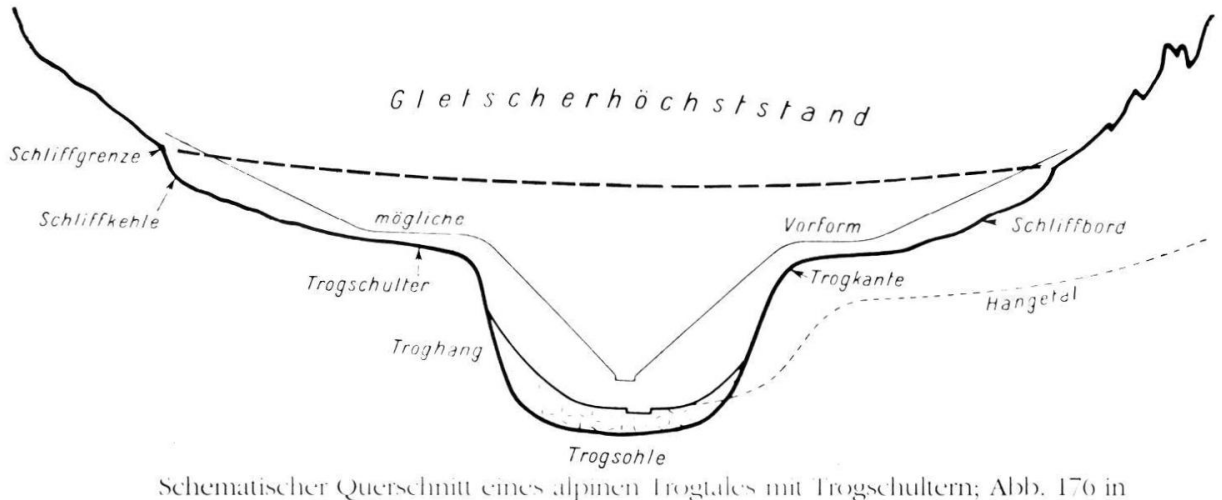

Anlehnung an Louis/ 1952 .

An den Flanken des Troges Hangschutt, auf der Sohle Grundmoräne und Schotter, darin eingetieft das Bett des heutigen Flusses.

Abb. 7: Querprofil über ein Trogtal mit Trogschultern (aus Weber 1967: 234, korrigiert "). Näheres im Text.

Fig. 7: Cross-section of an U-shaped valley with shoulders (from WeBer 1967: 234, revised" ). For details see text.

Diskontinuitäten im Längsprofil glazial überformter Täler in abrupten Wechseln des vertikal wirkenden Drucks des auflastenden Eises zu suchen ist (vgl. dazu u. S. 113).

Dennoch bleibt die Beschäftigung mit dem LouisModell anregend. Führt man nämlich den Vergleich mit den tatsächlichen Verhältnissen (Abb. 4) weiter, so zeigt sich, daß allenfalls die höchste Stufe des Tallängsprofils im Niveau der Eisbedeckung während der Gletscherhöchststände liegt, die übrigen jedoch zum Teil weit darunter. Das heißt aber, daß die Diskontinuitäten des Längsprofils - gleich, ob man sie durch das Louis-Modell oder anders erklärt - jedenfalls nicht während der Gletscherhöchststände entstanden sein können. Die waren ein Überflutungsphänomen, das alle Gefällsbrüche unterschiedslos überdeckte, aber nur selten und kurzfristig gegeben war und deswegen in den erreichten maximalen Höhenlagen auch nur schwach erosiv wirksam werden konnte. Die differenzierte, aber sehr viel intensivere Erosion der tieferen Lagen dagegen kann nur von kleineren Gletschern bewirkt worden sein, wie sie - für eine sehr späte Phase - die Ufermoränen der postglazialen Hochstände andeuten. Derartige, auf die Talgründe beschränkte Gletscher muß es im Pleistozän sehr viel häufiger gegeben haben als Gletscherhöchststände. Das hieße aber, daß die Diskontinuitäten der Längsprofile u. a. auch - eine Folgewirkung unterschiedlich lang andauernder Erosionstätigkeit der Gletscher sind, mit anderen Worten: daß für die Details glazialer Formung der Faktor Zeit eine wichtige Rolle spielt.

Die Konzentration der glazialen Erosion auf die tiefen Lagen des Längsprofils macht auch das Querprofil der Trogtäler mit Trogschulter verständlich, das Louis (1952) ebenfalls diskutiert hatte. In Anleh nung an PENCK (1912) machte er darauf aufmerksam, daß ein solches Querprofil (Abb. 7) zwei Punkte verstärkter glazialer Erosion aufweise, nämlich unterhalb der Schliffgrenze und unterhalb der Trogkante, gab aber ausdrücklich keine Erklärung dafür. Sie ist jedoch relativ einfach, wenn man akzeptiert hat, daß das Hauptcharakteristikum aller glazial geformten Täler - die Aufweitung des Talbodens und die Versteilung der Talhänge - eben nicht durch die Gletscher des Höchststandes geschaffen wurde, sondern durch vielfach wiederholte Vorstöße relativ geringmächtiger Gletscher in Phasen geringerer Vereisung ${ }^{5}$ ), während die - seltener eintretenden und einen viel breiteren Talquerschnitt betreffenden Gletscherhöchststände vorwiegend die Abtragung im Bereich der Schliffborde bewirkten.

Ein weiteres Verdienst des Louisschen Aufsatzes von 1952 (vgl. dazu auch Louis/Fischer 1979) ist schließlich, darauf aufmerksam gemacht zu haben, daß für die Höchststände der pleistozänen Gebirgs-

4) Weber hatte - wie vor ihm schon Schwarzbach (1964) - in das LouIs-Profil von 1952 zusätzlich die Eishöhe während des Gletscherhöchststandes eingetragen, er dachte sie sich leicht konvex gewölbt. Das ist jedoch eindeutig falsch. Denn gewölbte Oberflächen sind das Charakteristikum des Gletscherzehrgebietes, im Nährgebiet ist die Oberfläche mehr oder weniger eben, allenfalls schwach konkav durchgebogen. Die gesamten Alpen waren aber während des Gletscherhöchststandes mit Sicherheit Gletschernährgebiet. Also kann die Gletscheroberfläche in den Alpentälern während des Höchststandes jedenfalls nicht gewölbt gewesen sein. Darauf hat Lours selbst mehrfach und an prominenter Stelle hingewiesen (zuletzt in Louis/FISCHER 1979: 459 ff. und Anm. 31). Gleichwohl hat sich die fehlerhafte Darstellung („nach LouIs aus WEBER") bis heute in den Lehrbüchern gehalten ( $\mathrm{z}$. B. WILHELMY 1992).

5) Der Gedanke ist nicht neu, er findet sich bereits bei PHILIPPSON (1912). 
vereisungen mit klimatischen Verhältnissen gerechnet werden muß, die ein vom heutigen abweichendes Bewegungsverhalten der Gletscher bewirkt haben müssen. Louis hat darauf hingewiesen, daß die hochkaltzeitlichen Gletscher - wegen der durch den Permafrost auch noch in den tiefgelegenen Gebieten Mitteleuropas belegten sehr niedrigen Jahresmitteltemperaturen - durchweg kalte Gletscher gewesen sein und sich deswegen anders bewegt haben müssen als heutige Gletscher. Ein wesentliches Glied seiner Argumentation ist die von ihm sog. „Righeit“, also die relative Starrheit des bewegten Eises: damit vor allem erklärt er die „Blockschollenbewegung“ kaltzeitlicher Gletscher. Wie weit man dieser Argumentation im einzelnen folgt, ist - wie gesagt - eine andere Frage. Zweifellos aber ist der Hinweis auf die klimabedingt niedrigen Temperaturen des bewegten Eises während der Kaltzeiten des Pleistozäns wichtig.

Man muß sich in diesem Zusammenhang freilich vor einer Überstrapazierung des Aktualitätsprinzips hüten, darf also die pleistozänen kalten Gletscher Mitteleuropas nicht ohne weiteres mit heutigen kalten Gletschern der Zirkumpolarregion - etwa der Antarktis - vergleichen. Denn dort herrscht ein anderes Strahlungsklima als in den Mittelbreiten. In den Mit-

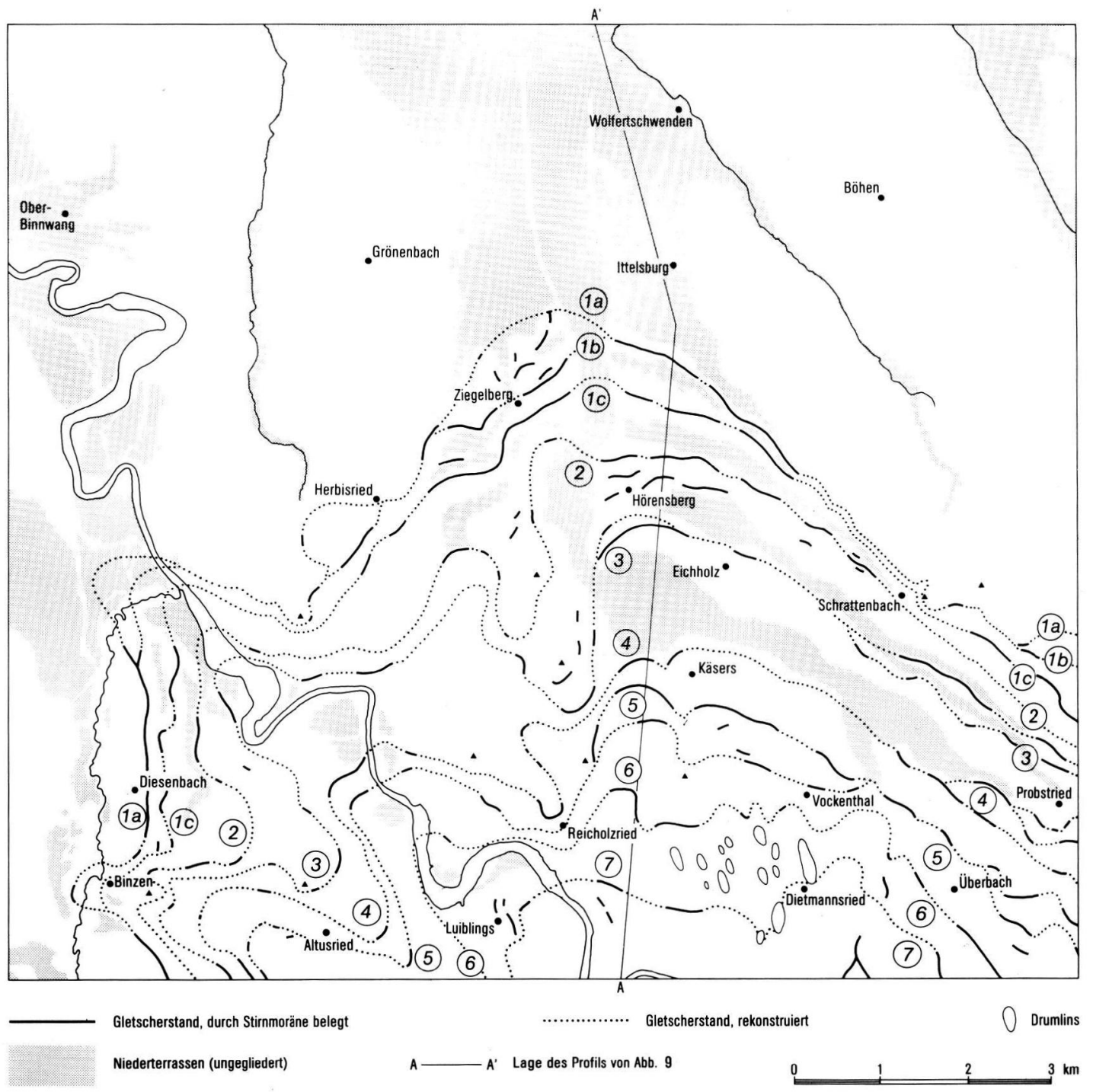

Abb. 8: Die Gletscherstände des hochwürmzeitlichen Illergletschers auf Blatt 8127 Grönenbach 1:25.000 (aus Habibe 1985: 63).

Fig. 8: The stades of the Würm Pleniglacial Iller glacier on sheet 8127 Grönenbach 1:25.000 (from HaBBE 1985: 63). 
telbreiten hat es auch während der Klimapessima des Pleistozäns ein ausgeprägtes Vier-JahreszeitenKlima (und nicht nur ein Zwei-Jahreszeiten-Klima wie in den Polargebieten) gegeben mit hohem Sonnenstand während des Sommers. Das war der Grund, weshalb auch während der Klimapessima in den Periglazialgebieten Mitteleuropas soviel Vegetation gedieh, daß sie den zahlreichen Großsäugern dieser Zeit als Nahrungsgrundlage ausreichte. Das heißt aber, daß die - durch den Permafrost belegten - niedrigen Jahresmitteltemperaturen zustande kamen durch eine Kombination relativ hoher Sommerund sehr niedriger Wintertemperaturen. Das wiederum bedeutet, daß es in den Frühjahrs- und Frühsommermonaten eine ähnlich rasche und intensive Schneeschmelzphase gegeben haben muß wie sie aus heutigen Subpolargebieten mit (relativ) kontinentalen Klimaverhältnissen bekannt ist ${ }^{6}$ ). Diese Klimagegebenheiten - mit sehr niedrigen Wintertemperaturen und hohem (Schnee-)Schmelzwasseranfall im Frühjahr und Frühsommer - müssen sich auch auf den Bewegungsmechanismus der hochkaltzeitlichen Gletscher ausgewirkt haben. Die Frage ist nur: wie? - und: wie läßt sich das feststellen?

Diese Fragen lassen sich jedenfalls nicht beantworten, indem man - wie das bisher in der Regel geschehen ist - Beobachtungen an rezenten Gletschern unbesehen auf kaltzeitliche Gletscher überträgt, und zwar vor allem deswegen nicht, weil die heutigen Gletscher seit etwa 1850 (mit kurzen Unterbrechungen) zurückschmelzende Gletscher sind, anders ausgedrückt: Gletscher mit negativer Massenbilanz. Das Charakteristikum hochkaltzeitlicher Gletscher

6) Vgl. dazu: McCann et al. (1972), СhurCh 1972, Flügel 1981, SCHUNKE 1981, 1989. war aber gerade umgekehrt, daß sie zu ihren Maximalständen v o r s t i e $ß$ e $\mathrm{n}$, dann in dieser Position längere Zeit oszillierten und schließlich rasch zurückschmolzen. Es handelte sich also um Gletscher mit zumeist ex́trem positiver Massenbilanz, unterbrochen nur durch kurze Phasen ausgeglichenen oder schwach negativen Massenhaushalts. Wie sie sich unter diesen Umständen bewegt haben, läßt sich naheliegenderweise am ehesten dort feststellen, wo sie ihre Maximalposition erreichten, d. h. nicht im Alpeninneren, sondern im Gebirgsvorland.

\section{Beobachtungen aus dem Gebiet des würmzeitlichen Illergletschers}

Eine Reihe eindrücklicher Hinweise auf den Bewegungsmechanismus hochkaltzeitlicher Vorlandgletscher liefert das Gebiet des würmzeitlichen Illergletschers (Abb. 8).

Die den rechten Rand des Gletschers nachzeichnenden Kame-Terrassen zeigen ein von den älteren zu den jüngeren Terrassen gesetzmäßig (von 14,6 auf $6,0 \%$ abnehmendes Längsgefälle (Abb. 9) und beweisen damit, daß die zugehörigen Gletscher bei ihren Vorstößen ebenfalls ein zunehmend geringeres Gefälle aufwiesen. Sie zeigen außerdem, daß die jüngeren Gletscher trotz entsprechend geringer werdender Mächtigkeit immer noch unverhältnismäßig weit vorstießen. Der Illergletscher blieb also bis zum Ende des Späthochglazials außerordentlich bewegungsaktiv, war somit trotz des Temperaturpessimums dieser Zeit nicht etwa - wie für die Gletscher des Maximalstands vielfach angenommen worden ist (Haeberli \& Penz 1985, Haeberli \& Schlüchter 1987) - unbeweglich geworden.
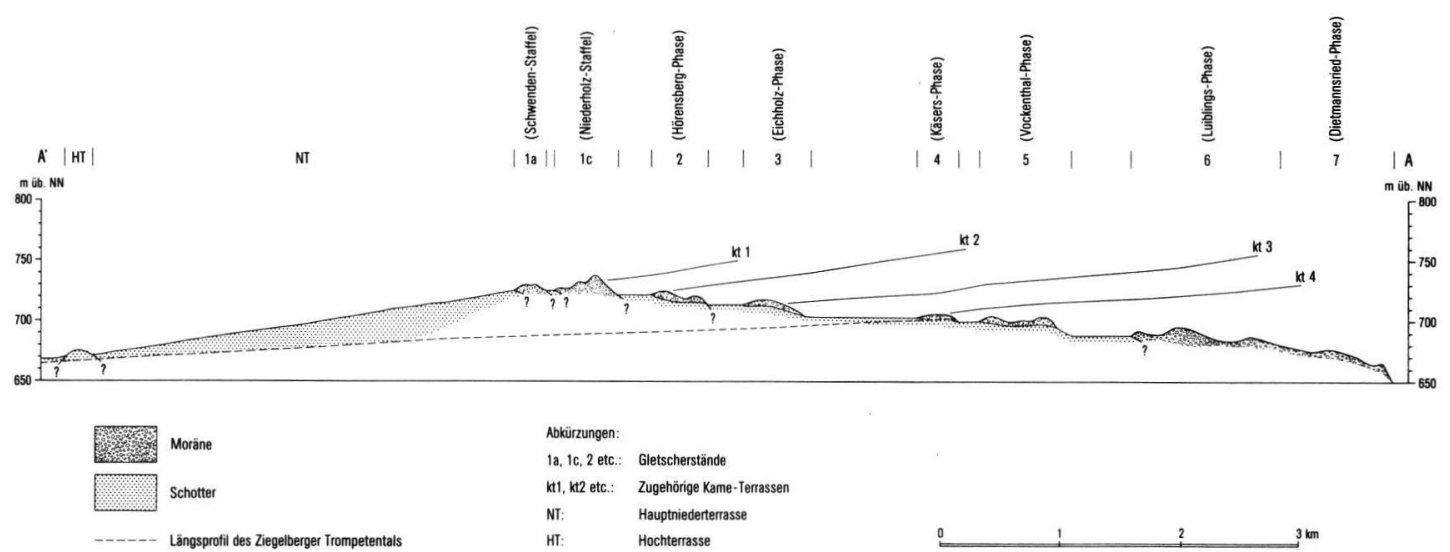

Abb. 9: Längsschnitt durch das Dietmannsriceder Zweiglecke'n des Illergletschers mit 10facher Überhöhung (aus HaBBE 1985: 59, leicht verändert).

Fig. 9: Longitudinal profile along the Dietmannsried branch basin of the Iller glacier. Vertical scale $10 \mathrm{x}$ exaggerated (from Habbe 1985 59, slightly altered). 


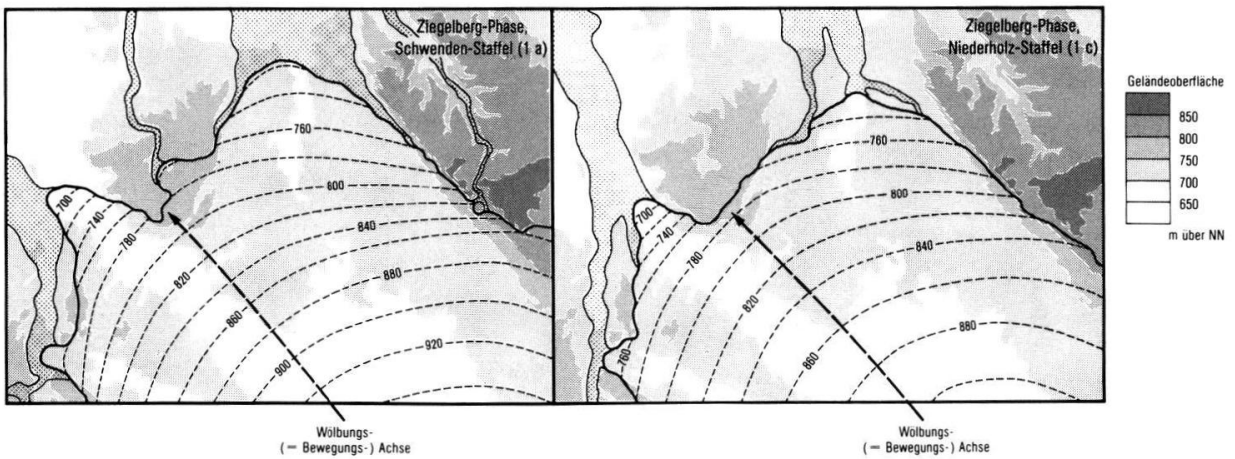

Abb. 10: Das Oberflächenrelief des Illergletschers während des Würm-Hochstandes (aus HaBbE 1985: 62, ergänzt).

Fig. 10: The surface relief of the Iller glacier during the Würm maximum (from HaBbe 1985: 62, complemented).

Wichtiger noch ist eine weitere Beobachtung. Da der Illergletscher nicht - wie alle anderen Gletscher des deutschen Alpenvorlandes - im flachen Molassevorland endete, sondern auf die proximalen Enden hochgelegener Schotterablagerungen älterer Eiszeiten auffuhr, liegt der Gürtel seiner äußeren Endmoränen ganz unterschiedlich hoch. Anhand seines Verlaufs läßt sich die Oberfläche des Gletschers zuverlässig rekonstruieren (Abb. 10). Deren Wölbungsachse - und damit die Stoßrichtung des Gletschers - zielte während des Maximalstandes nicht gegen den Hauptschmelzwasserabfluß - das altangelegte und sehr breite Memminger Trockental -, sondern gegen den höchsten Punkt der Gletscherumrahmung, den Sommersberg fast $100 \mathrm{~m}$ darüber. Der Gletscher muß sich also unabhängig vom Untergrundrelief bewegt haben und zeigte dabei eine ausgeprägte Tendenz zur Abweichung nach links.

Diese Tendenz zur Linksabweichung ist kein lokaler Sonderfall. Sie findet sich - mehr oder weniger deutlich - bei allen Vorlandgletschern sowohl im nördlichen Alpenvorland ${ }^{7}$ ) wie am Alpensüdrand ${ }^{8}$ ), sie läßt sich auch für die postglazialen Gletscherhochstände nachweisen"), und sie ist schließlich der

7) Eindrucksvollstes Beispiel ist der Isar-Loisach-Gletscher, der wesentlich von - über den Fernpaß und den Seefelder Sattel (nach links!) drängendem - inneralpinem Inn-Eis gespeist wurde, und dessen (linker!) Loisach-Ast am weitesten nach Norden vorstieß. Prinzipiell ähnlich aber auch der Rheingletscher (KraYss \& KelLER 1983)

8) Hier ist der wohl eindrücklichste Beleg die "Serra" an der Ausmündung des vom Mt. Blanc herabziehenden Dora-Baltea-Tales ( „die größte Moräne der Alpen" - so A. PENCK in PencK \& BRÜCKNer 1901-09: 762) auf der Ost-(der linken!)Flanke des Moränen-Amphitheaters von Ivrea.

9) Ein Beispiel dafür - unter vielen - bietet der Sulzenauferner (Abb. 3): er hat während der postglazialen Hochstände das Becken oberhalb der Sulzenau-Hütte nicht auf der vollen Breite erfüllt, sondern - weil nach links drängend - die große rechtsseitige Ufermoräne aufgeschüttet, hinter der die Blaue Lacke liegt.
Grund dafür gewesen, daß sich die Stoßrichtung der Vorlandgletscher von Eiszeit zu Eiszeit auch großräumig - und immer nach links abweichend ändern konnte ${ }^{10}$ ).

Sie war nur möglich, wenn die Gletscher sich in ihren oberflächennahen Partien anders bewegen konnten als in den basalen. Das setzt Trenn- und Gleitflächen im Gletscherkörper voraus, also \pm oberflächenparallele Scherflächen. Das über diese Scherflächen vorwärtsbewegte Eis kann - wie die Längsprofile zeigen (Abb. 5, Abb. 9) - nicht sehr mächtig, muß aber flächenmäßig recht ausgedehnt gewesen sein: es muß sich also um flache „Eisschilde“ gehandelt haben. Bewegungsmoment kann nicht - wie bei heutigen Gletschern zumeist - schwerkraftinduziertes Eisfließen, sondern muß ein - gleichfalls schwerkraftinduzierter - Schub gewesen sein, auf den das bewegte Eis (überwiegend) starr (jedenfalls nicht durch Verformung) reagierte. Ausgelöst worden sein kann diese Schubbewegung nur durch Massenüberschüsse im Nährgebiet, deren Ursache nach Lage der Dinge nicht Temperatur-, sondern Niederschlagsschwankungen gewesen sein dürften.

10) Auf der Alpennordseite ist dafür das beste Beispiel wiederum der Illergletscher: sein Zungenbecken erstreckte sich bis zur Mindel-Eiszeit in gerader Fortsetzung des inneralpinen Tales von Kempten in das (heutige) Wildpoldsrieder Zweigbecken, in der Mindel-Eiszeit wurde das westlich (links!) angrenzende Dietmannsrieder Zweigbecken, in der Riß-Eiszeit das - wiederum westlich benachbarte - Altusrieder Zweigbecken besetzt. Auch der Wechsel des Hauptschmelzwasserabflusses während des Hochstands der Würm-Eiszeit - vom (heutigen) Memminger Trockental in das IllerCanyontal - gehört in diesen Zusammenhang.

Auf der Alpensüdseite ist die Linksverschiebung der Gletscherachse am besten erkennbar an der räumlichen Anordnung von Alt- und Jungmoränen des Gardasee-Gletschers (Penck \& BRÜCKNER 190109, Habbe 1969, zuletzt Cremaschi 1987). In die gleiche Richtung deutet die Konfiguration des Gardaseebeckens (Tiefenkarte bei HaBBe 1969, Beilage 4): das tiefe Stammbecken zielt in Richtung des inneralpinen Tales gegen Südwest, das flache, jenseits des Rückens von Sirmione nach Osten sich erstreckende Teilbecken von Peschiera ist vom Gletscher erst in der Riß-Eiszeit besetzt worden. 


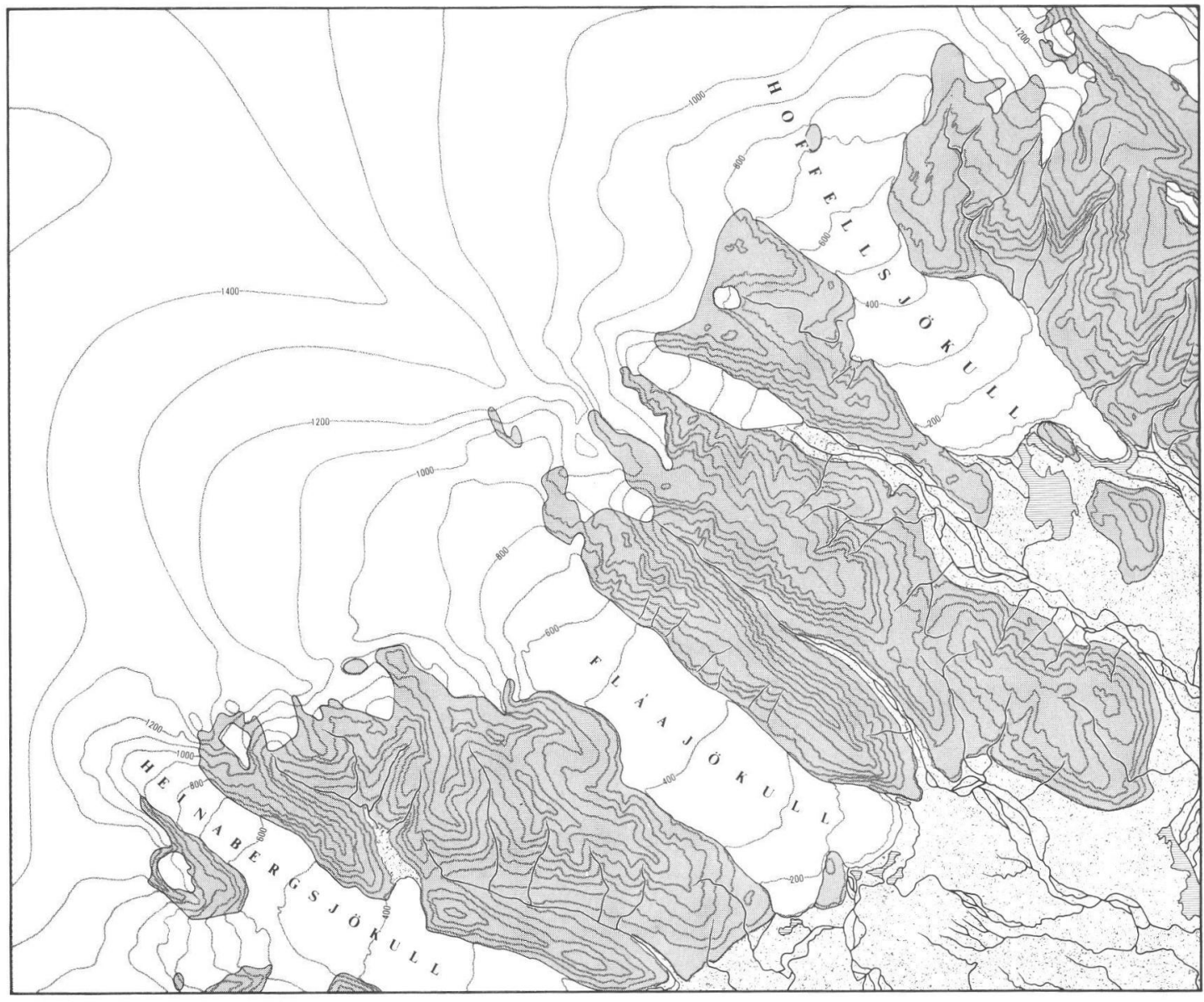

Felsflächen

2.2. Aufschüttungsflächen

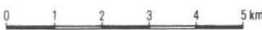

Abb. 11: Die Südostflanke des Vatnajökull/Island (nach Uppdráttur Islands 1:100.000, Blad 96 Hoffellsjökull). Die Karte zeigt den Gletscherstand von 1969, also vor dem 1960/90er Vorstoß, läßt aber gleichwohl die Tendenz der Gletscherzungen nach links, die der austretenden Schmelzwässer nach rechts erkennen.

Fig. 11: The southeastern flank of the Vatnajökull in Iceland (after Uppdráttur Islands 1:100.000, Blad 96 Hoffellsjökull).

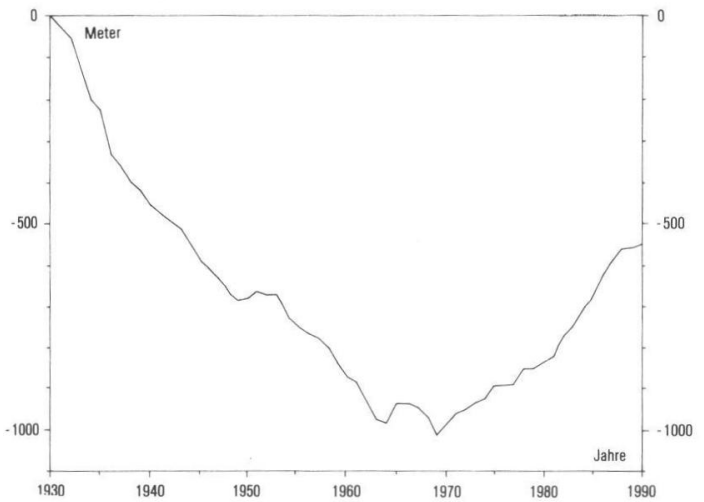

Abb. 12: Schwankungen des Zungenendes des Sólheimajökull - eines Fußsgletschers des Myrdalsjökull - seit 1930 (nach NORDDAHL 1994, umgezeichnet).

Fig. 12: Variations of the glacier front of the Sólheimajökull since 1930 (after NORDDAHL 1994, redrawn).

\section{Beobachtungen an rezenten Gletschern in Island}

Für diese Art Bewegungsmechanismus gibt es aktuelle Belege von Fußgletschern des Vatnajökull in Island (Abb. 11). Die isländischen Gletscher sind wie viele Alpengletscher auch - seit den späten 60er bis in die 90er Jahre vorgestoßen (Abb. 12), jedoch nicht nur - wie die Alpengletscher - um einige Dekameter, sondern um mehrere Hektometer. Wie bei den Alpengletschern handelt es sich dabei um Vorstöße, die nicht durch Temperatur-, sondern durch Niederschlagsschwankungẹn ausgelöst wurden.

Wie die isländischen Fußgletscher sich dabei bewegten, läßt sich am Ost- (dem linken!)Flügel des Hoffellsjökull beobachten (Abb. 13). Dort zeigt sich, daß der vorstoßende Gletscher nicht als Ganzes 


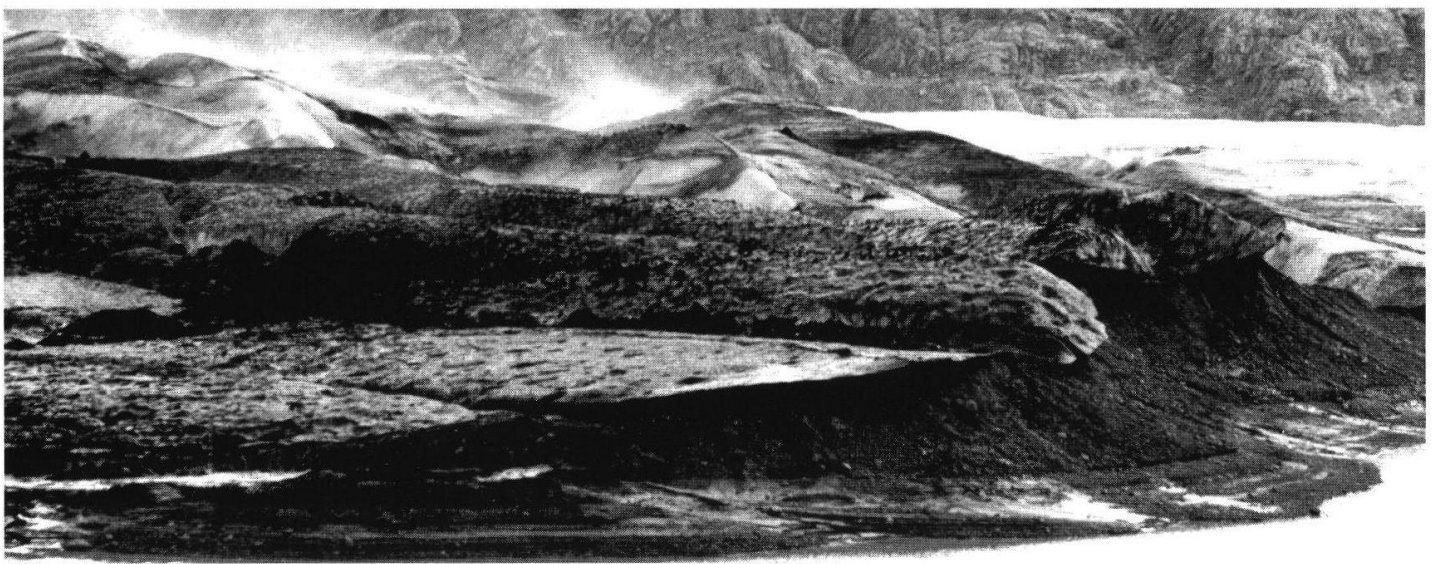

Abb. 13: Das östliche Zungenende des Hoffellsjökull, vom rechten Talhang her gesehen (Aufn. Verf. 19.8.1994). Näheres im Text.

Fig. 13: The eastern lobe-end of the Hoffellsjökull, seen from the right valley slope (phot. K.A.H. 19.8.1994). For details see text.

sich bewegt hat, sondern tatsächlich mehrere (fünf) dünne Eisschilde teleskopartig übereinander hinweg bewegt wurden, die alle aus der Vorstoßphase der 60er/90er Jahre stammen. Man erkennt deutlich deren Tendenz zur Abweichung nach links, und man sieht, daß die Gleitflächen zwischen den Eisschilden gebildet werden von den niedergeschmolzenen Oberflächen vorhergehender Vorstöße.

Abb. 14 von der Stirn des benachbarten Fláajökull belegt, daß die Eisschilde trotz nur geringer Mäch- tigkeit tatsächlich ohne Verformung selbst gegen beträchtliche Gegengefälle - hier die Endmoräne des $60 \mathrm{er} / 90 \mathrm{er}$ Vorstoßes - (und darüber hinaus) vorwärts g e s c h o b e n werden (und nicht etwa „fließen“). Abb. 15 schließlich zeigt, daß diese Schubbewegung kein Einzelfall ist, sondern ein rhythmisches Phänomen, das sich allsommerlich wiederholt. Nur hat der Schub in diesem Fall nicht ausgereicht, um die Stirn der vorstoßenden Eisschilde bis über die Krone des Endmoränenwalles hinaus vorzuschieben. Die an

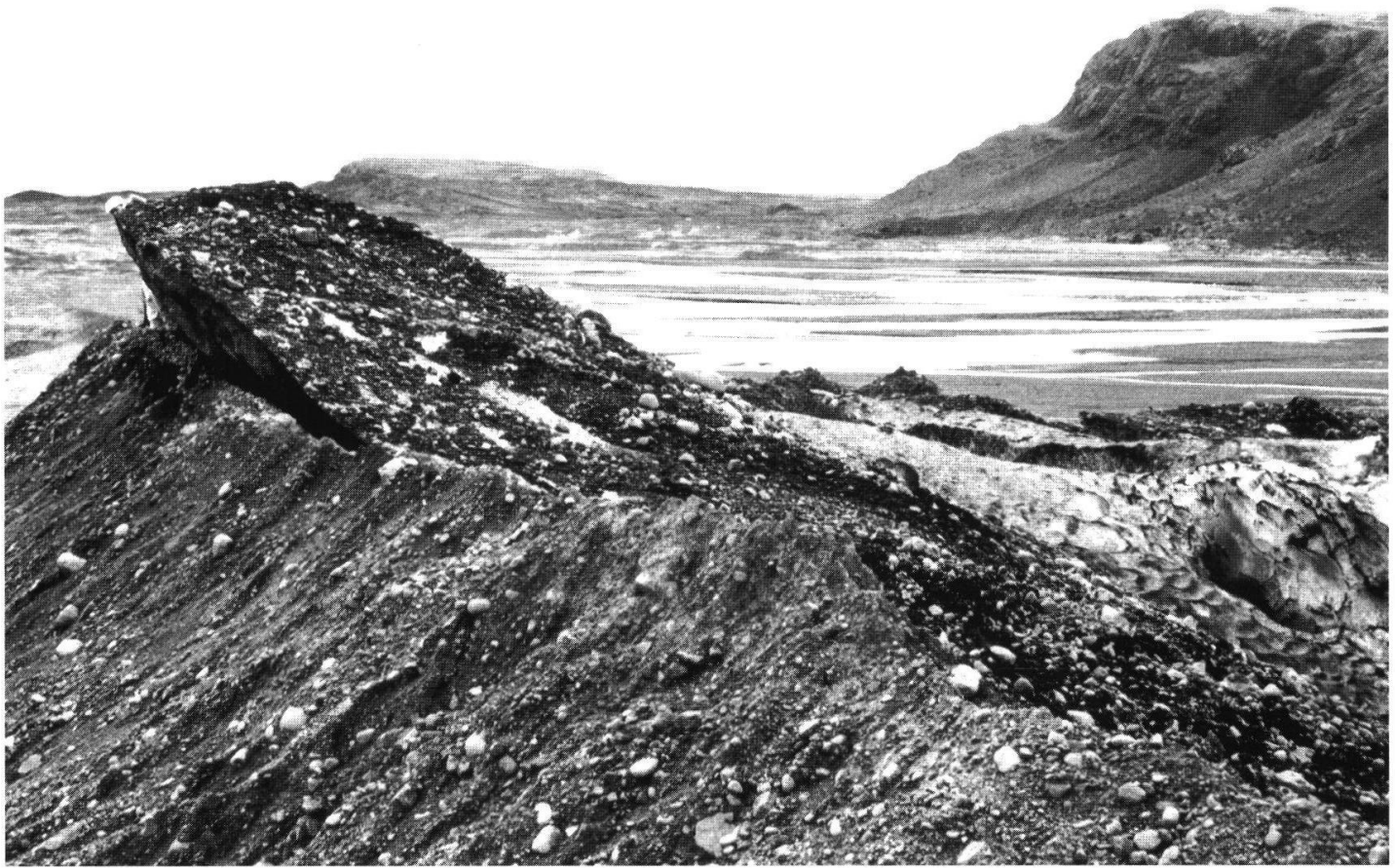

Abb. 14: Ein dünner Eisschild des vorstoßenden Fláajökull schiebt über die Krone der Endmoräne des gleichen Vorstoßes hinaus (Aufn. Verf. 19.8.1994).

Fig. 14: A thin ice-shield of the advancing Flajojoull is moved by pressure from the rear across the crest of the terminal moraine of the same glacial advance (phot. K.A.H. 19.8.1994). 


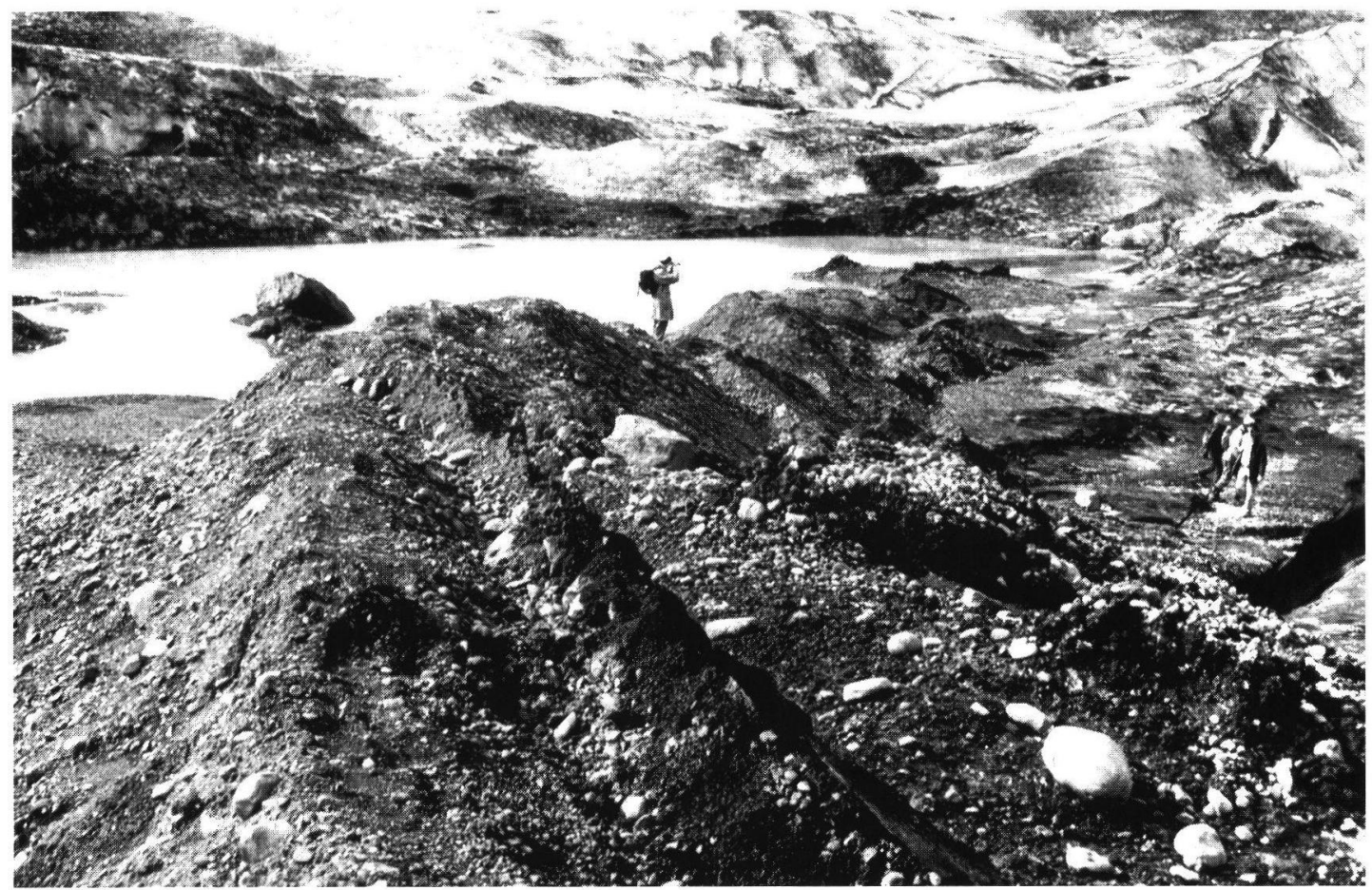

Abb. 15: Drei „Jahresmoränen“ des Fláajökull, angeschuppt an den Innenhang der Endmoräne des 1960/90er Vorstoßes (Aufn. Verf. 19.8.1994)

Fig. 15: Three "annual moraines" of the Fláajökull, imbricated at the inner slope of the 1960/90 advance (phot. K. A. H. 19.8.1994)

der Basis des Eisschildes mitgeschleppte Moräne ist daher nicht über den Außenhang der Endmoräne .,abgekippt“, sondern an deren Innenhang als ,Jahresmoräne" abgelagert (,angeschuppt") worden. Aber auch hier zeigt sich, daß die Eisschilde ohne Verformung auch gegen Gegengefälle vorwärtsgeschoben werden.

\section{Folgerungen}

Es läßt sich also zeigen, daß der für den hochkaltzeitlichen Illergletscher zunächst nur erschlossene Bewegungsmechanismus in allen Einzelheiten auch bei rezenten Fußgletschern des Vatnajökull nachweisbar, also jedenfalls nicht nur ein theoretisches Konstrukt ist. Danach erscheint es erlaubt, die Vorwärtsbewegung auch vorstoßender kaltzeitlicher Gletscher zu erklären als Summation zahlreicher, relativ kurzdauernder und nur relativ kleine Distanzen überbrückender, durch Rück- und Niederschmelzphasen voneinander getrennter Vorschübe flacher Eisschilde auf oberflächennahen Scherflächen über stagnierendem Eis vorhergehender Vorstöße.

Dieser - durch Niederschlags- und nicht durch Temperaturunterschiede gesteuerte und durch Reibungsverluste kaum behinderte - Bewegungsmechanismus macht eine Reihe bisher schwer erklärba- rer Phänomene verständlich, z. B. weshalb überhaupt die - im Verhältnis zu ihrer Flächenausdehnung außerordentlich dünnen und sehr flach geböschten (Abb. 15) - kaltzeitlichen Gletscher so weit vorgestoßen sind wie sie das tatsächlich getan, und weshalb sie auch in der Maximalposition noch kräftig oszilliert haben, oder weshalb sich die morphostratigraphische Gliederung des letztkaltzeitlichen Späthoch- und Spätglazials sowohl im Alpenvorland wie auch im nördlichen Mitteleuropa in der aus den Tiefseebohrkernen gewonnenen Sauerstoffisotopenkurve nicht abbildet (HABBE 1995).

Er hat aber vor allem auch Konsequenzen für die Erklärung der glazialen Erosion und Übertiefung. Er impliziert nämlich, daß eine Einwirkung der vorstoßenden Gletscher auf den Untergrund nur dort (und dann) möglich war, wo (und wenn) sie über ihre stagnant-ice-Unterlage vorstießen, d. h. jeweils nur in dem Bereich zwischen dem Außenrand der Eisunterlage und der Gletscherstirn (Abb. 16). GröBeres Ausmaß konnte sie nur dann erreichen, wenn dem Gletschervorstoß ein längerdauernder Gletscherhalt in der erreichten Maximalposition - also eine Phase ausgeglichenen Massenhaushalts - folgte, und glaziale Übertiefung war unter diesen Umständen nur möglich, wenn zusätzlich unter hohem hydrostatischem Druck stehendes (Schnee-)Schmelzwasser auf den Untergrund einwirkte. 

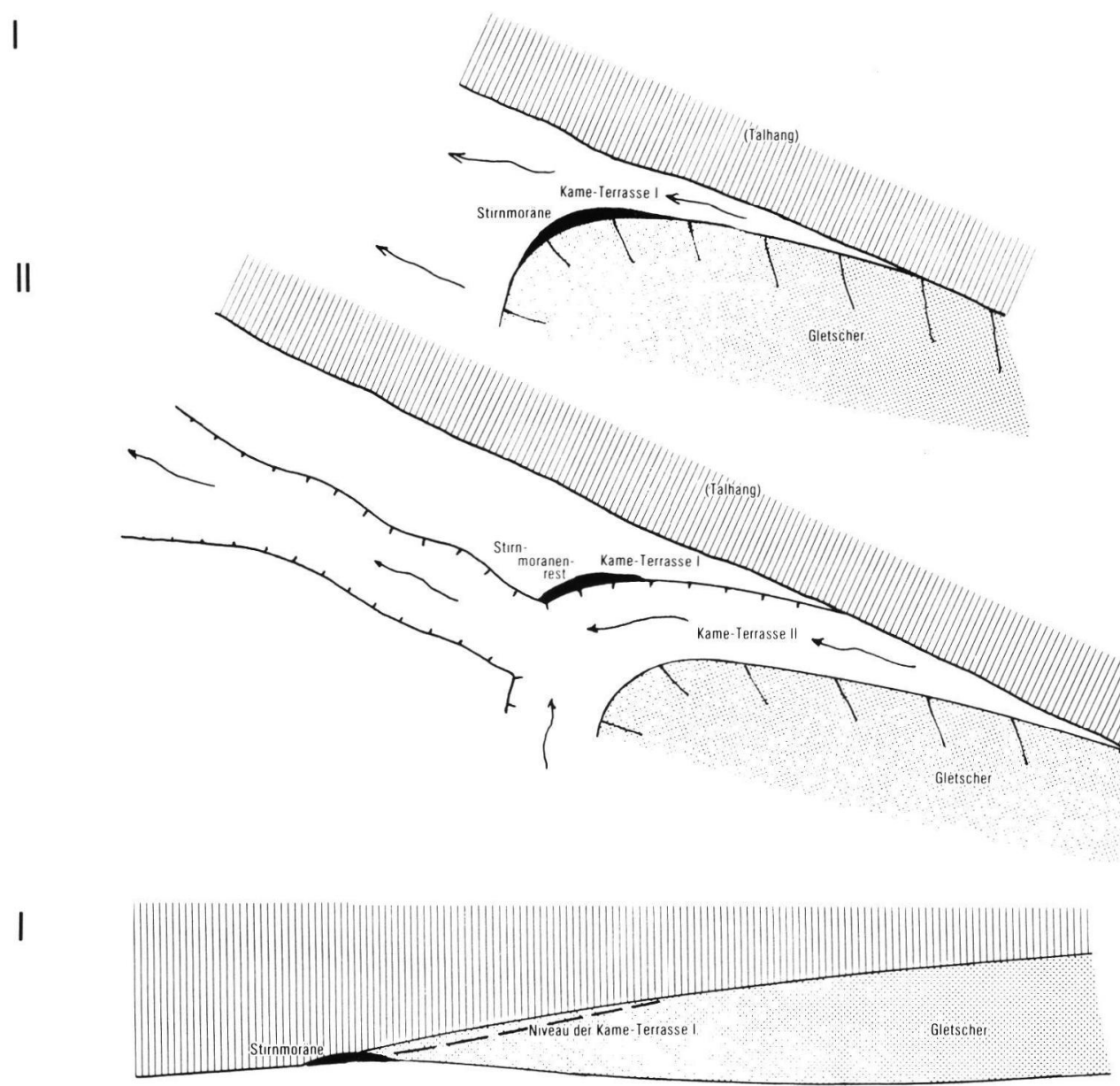

la

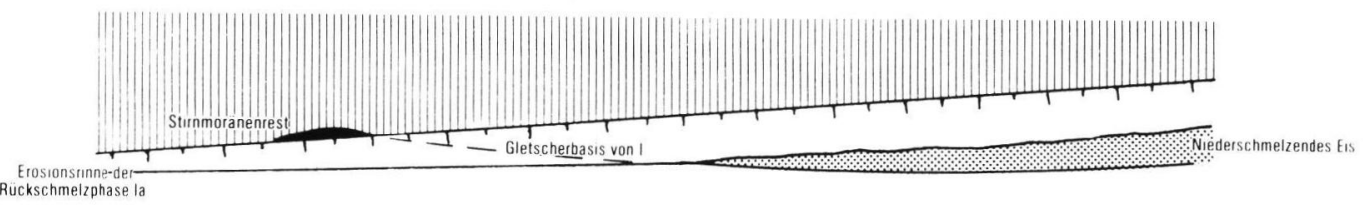

II

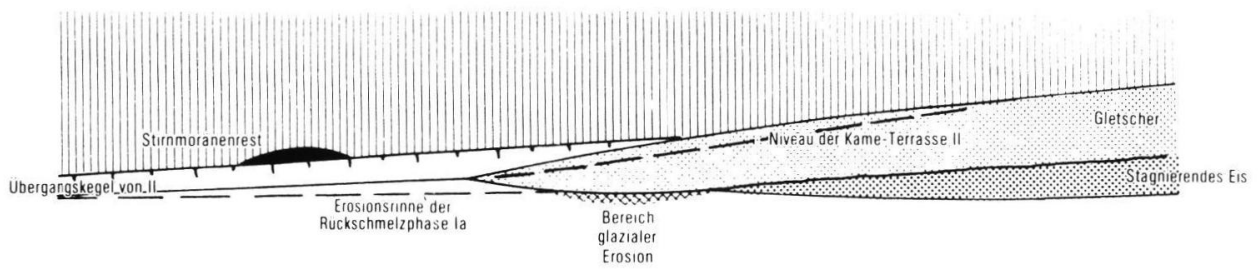

Abb. 16: Der Bewegungsmechanismus eines vorstoßenden Gletschers, in Anlehnung an die Verhältnisse beim würmzeitlichen Iller-Gletscher. Oben Grundrisse, unten zugehörige Längsprofile. I = Maximalstand, II = Internstand, Ia = die zwischen I und II anzunehmende, im Gelände nicht dokumentierte Rück- und Niederschmelzphase. Der zu Stand II vorrückende Gletscher hat das stagnierende Eis der Niederschmelzphase überfahren. Glaziale Erosion war dabei nur möglich im Bereich zwischen Gletscherstirn und distalem Ende der stagnant-ice-Unterlage.

Fig. 16: The motion mechanism of an advancing glacier according to the situation in the area of the Würm Pleniglacial Iller glacier. Schematic ground-plans above, appertaining longitudinal profiles below. I $=$ maximum stade, II $=$ internal stade, Ia $=$ the back-anddown-melting phase to be assumed between I and II, but not documented in the field. The glacier advancing to stade II has overridden the stagnant-ice of the down-melting phase. Glacial erosion during phase II was possible only between the glacier front and the distal margin of the stagnant-ice basement. 


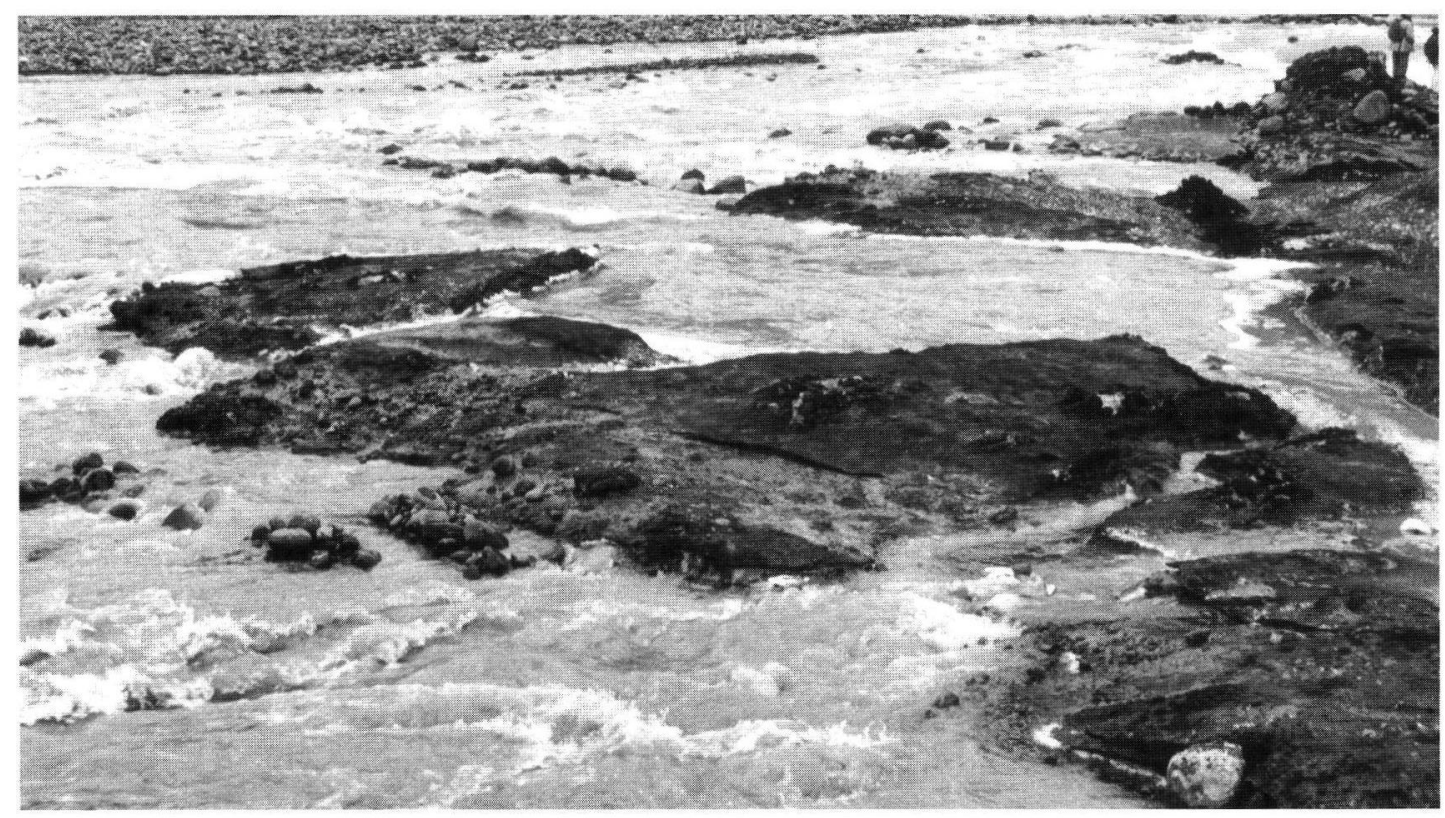

Abb. 17: Unter hydrostatischem Druck aus niedergeschmolzenem Eis des Fláajökull austretendes Schneeschmelzwasser (Aufn. Verf. 19.8.1994).

Fig. 17: Snow meltwater upwelling under hydrostatic pressure from stagnant-ice of the Fláajökull (phot. K.A.H. 19.8.1994).

\section{Beobachtungen zur Schmelzwasser- bewegung in und unter dem Gletscher}

Eine solche Schmelzwasserbewegung unter hydrostatischem Druck ist für die kaltzeitlichen Gletscher des Alpenvorlands vielfach belegt dadurch, daß in den Füllungen der glazial übertieften Becken außer Beckenschluffen regelmäßig auch glazifluviale Kiese erbohrt wurden, und zwar stets an der Basis der Füllung ${ }^{11}$ ). Diese Kieslagen an der Basis beweisen, daß der hydrostatische Druck unter dem vorstoßenden Gletscher so groß war, daß das unter dem Gletscher bewegte Wasser nicht nur das auflastende Eis anheben und das - bei allen übertieften Becken gegebene - Gegengefälle überwinden konnte, sondern auch zu kräftigem Materialtransport - und damit zu Erosion - in der Lage war.

Unter hydrostatischem Druck stehendes Wasser an der Gletscherbasis tritt bei vorstoßenden Gletschern aber auch bei normalem Basisgefälle nach außen auf. Das läßt sich wiederum an einem rezenten Beispiel aus Island belegen.

Abbildung 17 - unmittelbar vor der Stirn des Fláajökull an dessen rechter Flanke aufgenommen -

11) Ein Beispiel dafür bietet Schreiner (1973: 36, Abb. 5). Dort sind in einer Bohrung am Innenrand des Markelfinger Winkels - bei Radolfzell im westlichen Bodenseegebiet - durch entsprechende Kiesbasislagen zwei aufeinanderfolgende Eintiefungsphasen angedeutet. Diese Bohrung ist - vereinfacht - in die Profildarstellung Abb. 20 der vorliegenden Arbeit einbezogen worden. scheint zunächst nur einen normalen Schmelzwasserabfluß zu zeigen. Das Besondere daran ist, daß die "Landzungen“ zwischen den abfließenden Wasserläufen nicht allein aus Schottern, sondern vor allem aus Gletschereis bestehen, und das Wasser nur zum Teil von der Gletscherfront abfließt, in der Hauptsache aber - wie bei artesischen Quellen - von unten her aufdringt, augenblicksweise regelrechte Fontänen bildend (was auf rasch wechselnde Druckverhältnisse hinweist).

Abbildung 18 (oben) zeigt die Situation im Längsschnitt. Sie läßt sich nur erklären, wenn man (Abb. 18, unten) annimmt, daß sich das in den Gletscher eingedrungene Schneeschmelzwasser auf den gleichen Scherflächen bewegt wie das Eis selbst vorzugsweise auf der obersten -, daß die Eisschilde für das Wasser normalerweise - vermutlich wegen des Drucks von hinten - undurchdringlich sind, und das Wasser im vorliegenden Fall nur deswegen an die Oberfläche quillt, weil der Niedertauprozeß nach Abschluß der Vorstoßphase den abdeckenden Eisschild hier extrem dünn und damit durchlässig hat werden lassen. Bevor diese Situation eintrat, muß das Schmelzwasser jedoch unter dem Eis bis an die Gletscherfront vorgedrungen sein und entsprechend auf den Untergrund eingewirkt haben. Dabei könnte - darauf weisen die heute noch beobachtbaren Druckschwankungen hin - wegen der rasch wechselnden Druckverhältnisse Kavitationskorrasion (mit der Folgewirkung besonders hoher Erosionsbeträge) wirksam gewesen sein. 

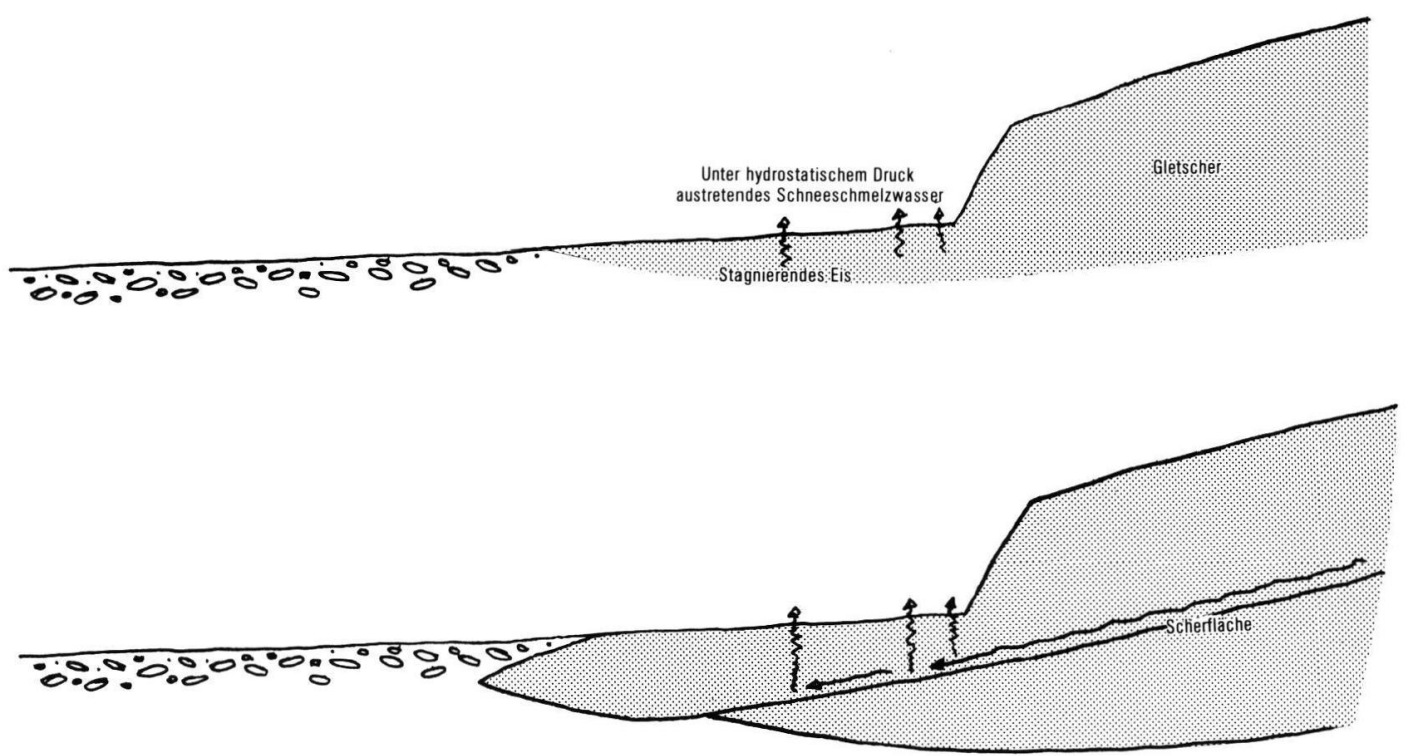

Abl. 18: Die Situation von Abb. 17 im schematischen Längsschnitt. Oben die beobachteten Phänomene, unten die Deutung. Näheres im Text.

Fig. 18: The situation of fig. 17 in a schematic longitudinal profile. Above the phenomena observed, below the interpretation. For details see text.

Der artesische Aufstieg des Schmelzwassers läßt sich im übrigen nur im Sommer beobachten, er ist also an die Zeiten hohen Wasserandrangs während der Schneeschmelze gebunden.

\section{Folgerungen}

Kräftigere glaziale Erosion, insbesondere aber glaziale Übertiefung wäre danach vor allem durch subglaziale Schmelzwassererosion bedingt und ein nicht nur örtlich, sondern auch zeitlich beschränktes Phänomen, ist das sicher auch unter kaltzeitlichen Bedingungen gewesen. Sie muß in den wenigen Wochen der Schneeschmelze - in denen allein sie möglich war - sehr intensiv auf den Untergrund eingewirkt haben. In wie starkem Maße das der Fall war, hing einerseits von der zur Verfügung stehenden Wassermenge $a b$, andererseits vom Wechselspiel zwischen hydrostatischem Druck und Eisauflast. Die Einwirkung auf den Untergrund muß also gegen die Gletscherstirn hin ab-, gletscheraufwärts dagegen zugenommen haben, aber nur so weit, wie der hydrostatische Druck imstande war, das auflastende Eis anzuheben. Die von älteren Vorstößen herrührende stagnant-ice-Unterlage hat dabei als zusätzlich begrenzendes Moment gewirkt. Der absolute Betrag der Eintiefung hing in jedem Falle davon $\mathrm{ab}$, wie lange der Gletscher in der Position verharrte, die dieses Gegeneinander verschiedener Faktoren erst ermöglichte.
Die für die Quartärbasis der glazial geformten Täler der Alpen wie des Alpenvorlands so charakteristische Becken- und Schwellen-Struktur („die Diskontinuitäten des Längsprofils") wäre danach nicht - wie Louts (1952) unterstellte - auf abrupte Wechsel des Vertikaldrucks des auflastenden Eises zurückzuführen, sondern auf räumliche und zeitliche Diskontinuitäten der subglazialen Schmelzwasserdynamik im Bereich unmittelbar hinter der Gletscherstirn. Das erklärt, weshalb Becken und Schwellen im gesamten Längsprofil auftreten, also offenbar unabhängig sind von der nach außen abnehmenden Mächtigkeit (und damit des Vertikaldrucks) des Eises. Es bestätigt außerdem die oben (S. 104) getroffene Feststellung, daß die typischen Trogtalprofile nicht durch die Gletscher des Höchststandes, sondern durch die Vorstöße kleinerer, an den eigentlichen Taltrog gebundener Gletscher geschaffen wurden. Aus der räumlichen Beschränkung der Schmelzwassererosion auf den Bereich hinter der Gletscherstirn ergab sich die Becken-Schwellen-Folge in den Alpentälern und im Vorland: die Schwellen bezeichnen danach - vermutlich wiederholt erreichte - längerdauernde Randlagen sowohl der Gletscherstirn wie der stagnant-ice-Unterlage, die Becken den Bereich intensiver subglazialer Schmelzwassererosion dazwischen. Die zeitliche Begrenzung des Vorgangs dagegen erklärt, weshalb die subglaziale Ausräumung nicht immer und überall gleichsinnig wirksam war, weshalb also z. B. örtlich ältere Lockergesteinsmassen vom würmzeit- 
lichen Gletscher nicht - oder nicht vollständig - ausgeräumt wurden ${ }^{12}$ ): in diesen Fällen folgten die Gletschervorstöße so rasch aufeinander, daß die Zeit für die Ausräumung auch nur von Lockermaterial durch subglaziale Schmelzwassererosion nicht ausreichte.

\section{Weitere Beobachtungen zum Schmelzwasserverhalten im Gletscher und am Gletschersaum}

Offenbar war also glaziale Erosion, jedenfalls aber glaziale Übertiefung abhängig davon, daß unter hydrostatischem Druck stehendes Schmelzwasser hinreichend lange auf den Untergrund einwirken konnte. Ob das der Fall war, hing in den Alpentälern allein von der mehr oder weniger raschen Abfolge der Gletschervorstöße ab. Wegen ihres beengten Querschnitts dürfte Schmelzwasser hier stets und über die ganze Breite des Profils in ausreichendem Maße zur Verfügung gestanden haben. Im Alpenvorland lagen die Verhältnisse jedoch anders. Zwar trat hier während des Maximalstandes das anströmende Schmelzwasser - weil es sich im Gletscher auf oberflächennahen Scherflächen bewegte und nicht (wie bei heutigen Gletschern) bis zur Tiefenlinie unter dem Gletscher absank - an zahlreichen Stellen an der Gletscherstirn aus, war also nahezu ubiquitär vorhanden und wirksam. Aber während der Vorstoßphasen muß die Wasserführung in den Vorlandgletschern - und damit ihre Einwirkung auf den Untergrund - stärker linienhaft ausgerichtet gewesen sein und zwar aus zwei Gründen:

1. In stärker reliefiertem Gelände mußten sich die Gletscher auch im Vorland dem Untergrundrelief anpassen. Die subglaziale Schmelzwassererosion konzentrierte sich entsprechend auf dessen Tiefenlinien, insbesondere auf die gegen das Stammbecken ziehenden „zentripetalen" Täler, in denen der Gletscher talauf schob. Hier war von vornherein ein Gegengefälle gegeben und der hydrostatische Druck des unter dem Eis bewegten Schmelzwassers entsprechend hoch mit der Folge, daß relativ rasch übertiefte Zweigbecken entstehen konnten.

2. In offenerem Gelände wurde das auf den Scherflächen im Gletscher sich bewegende Wasser - weil die Eisschilde nach links tendierten - auf die ge-

12) Dafür ist das alpine Loisachtal (BADER 1979: 54, Abb. 3) ein Beispiel: von dessen mächtiger spätrißzeitlicher Lockergesteinsfüllung wurde vom würmzeitlichen Gletscher nur wenig ausgeräumt, und zwar offenbar deswegen nicht, weil der vorrückende Gletscher rasch bis an die Murnauer Molasseschwelle vorstieß und dann alsbald von einem weiteren Vorstoß überfahren wurde, so daß für subglaziale Schmelzwassererosion nach dem ersten Vorstoß wenig Zeit blieb und danach das stagnierende Eis dieses Vorstoßes den Untergrund gegen Schmelzwassererosion der nachfolgenden Vorstöße schützte, so daß sie nur weiter nördlich - im Riegsee-, im Spatzenhausen-Eberfinger (FrANK 1979) und im Ammersee-Becken wirksam werden konnte. genüberliegende, die rechte Flanke des Gletschers gezwungen ${ }^{13}$ )

Das auf den Scherflächen im Gletscher auf dessen rechter Flanke anströmende Schmelzwasser konnte - je nach den angetroffenen Geländeverhältnissen unterschiedliche Wirkungen entfalten: entweder subglazial erosiv wirksam werden oder an der Gletscherflanke austreten und dann - u. U. auch akkumulieren.

Für diesen zweiten Fall ist das Gebiet des würmzeitlichen Illergletschers wiederum ein eindrucksvolles Beispiel: so erklären sich die Kame-Terrassen, die an dessen rechter Flanke (und nur hier) als Äquivalente des Maximalstandes und der älteren Internstände des Gletschers auftreten (Abb. 8).

Der erste Fall - linienhaft gerichtete subglaziale Schmelzwassererosion auf der rechten Flanke eines Großgletschers - ist beim Rheingletscher durch das Zweigbecken des Überlinger Sees beispielhaft dokumentiert, aber z.B. auch beim Gardasee-Gletscher durch die Buchten von Padenghe und Salò.

Einen Mischtyp repräsentieren die Verhältnisse an der rechten Flanke des Untersees (Abb. 19 und 20). Hier liegen zwischen Konstanz und Markelfingen am rechten Ufer von Gnadensee und Markelfinger Winkel in einer Mächtigkeit von bis über $60 \mathrm{~m}$ die sog. „Markelfinger Kiese“. Einen Kieskern hat auch die Halbinsel Mettnau. Der dazwischenliegende Markelfinger Winkel ist glazial übertieft, ebenso das nördlich des Markelfinger Kiesbandes gelegene Mindelsee-Becken und die daran anschließende, oberflächlich durch jüngere glaziale und glazifluviale Ablagerungen maskierte "Güttinger Rinne“. Die beiden Kiesvorkommen liegen also auf langgestreckten Rücken zwischen übertieften Becken. Die Markelfinger Kiese überdecken zudem (stellenweise) eine gleichfalls übertiefte ältere Rinne. Die Markelfinger Kiese wie auch das Kiesvorkommen auf der Mettnau sind oberflächlich drumlinisiert (dazu: HabBe 1988, Ellwanger 1990). Stratigraphisch sind die Markelfinger Kiese bisher teils als spätrißzeitliche Rückzugsschotter oder würmzeitliche Vorstoßschotter (SCHREINER 1973), teils als würmzeitliche Kameterrassen-Ablagerungen (ELLWANGER 1990) gedeutet worden. Beide Annahmen setzen für die Zeit der Ablagerung ein völlig anderes Relief voraus als das heutige: die Markelfinger Kiese (wie die der Mettnau) können nur längs Tiefenlinien abgesetzt worden sein, nicht aber auf langgestreckten Rücken.

13) Diese Rechtstendenz des Schmelzwassers im Gletscher läßt sich anhand von dessen Austrittsstellen an der Gletscherfront an kaltzeitlichen Gletschern - besonders schön beim Rheingletscher, dessen Schmelzwässer zum größten Teil über hochgelegene Wasserscheiden an seiner rechten (!) Flanke zur Donau abflossen - ebenso beobachten wie an den heutigen Fußgletschern des Vatnajökull (Abb. 11) 


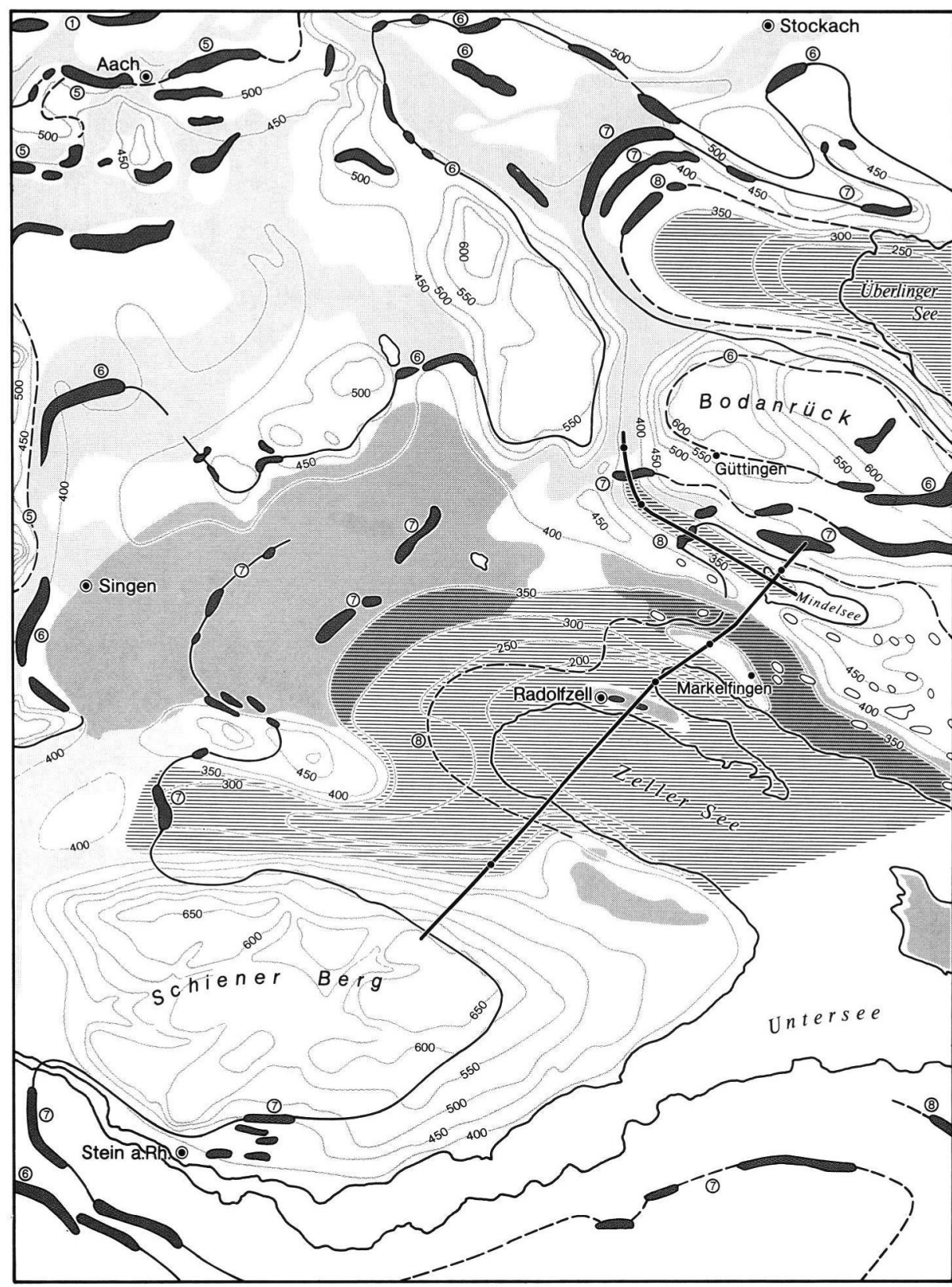

(6) Gletscherstände mit Endmoränen

Do Drumlins
Kame-Terrassen

Übertiefte Becken

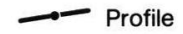

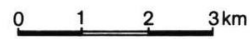

Schmelzwasserabflußwege

Abb. 19: Würmzeitliche Ablagerungen und Formen im Bereich des westlichen Untersees (nach SCHREINER 1968, 1970, ergänzt). Höhenkurven der Quartärbasis. Im Grenzbereich gegen die Schweiz fehlen die Daten, die Übertiefung ist daher dort nicht dargestellt.

Fig. 19: Würm Pleniglacial deposits and landforms in the area of the western Untersee (after SCHREINER 1968, 1970, complemented).

Contour lines of the Quarternary base. In the boundary area against Switzerland corresponding dates are lacking, the overdeepening is therefore not shown there. 


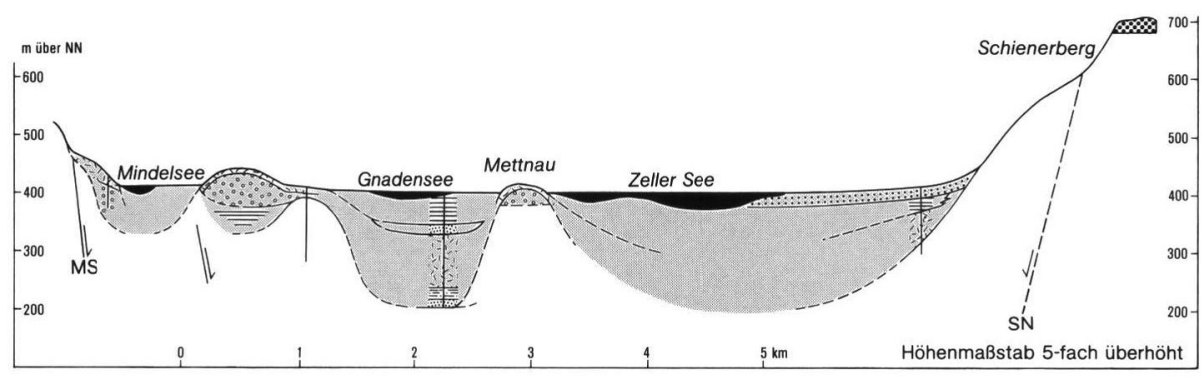

...:.: Sande

- Gi: Geschiebemergel (Würm)

$\because \because 2$ Rinnenschotter (Kameterrassen-Ablagerungen)

Beckenschluffe

Schluffe und Sande

Kiese

桨 Deckenschotter (Günz)

\|\|$_{j}^{\prime}$ Verwerfungen

MS Mindelsee-Verwerfung

SN Schienerberg-Nordrandverwerfung

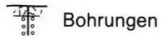
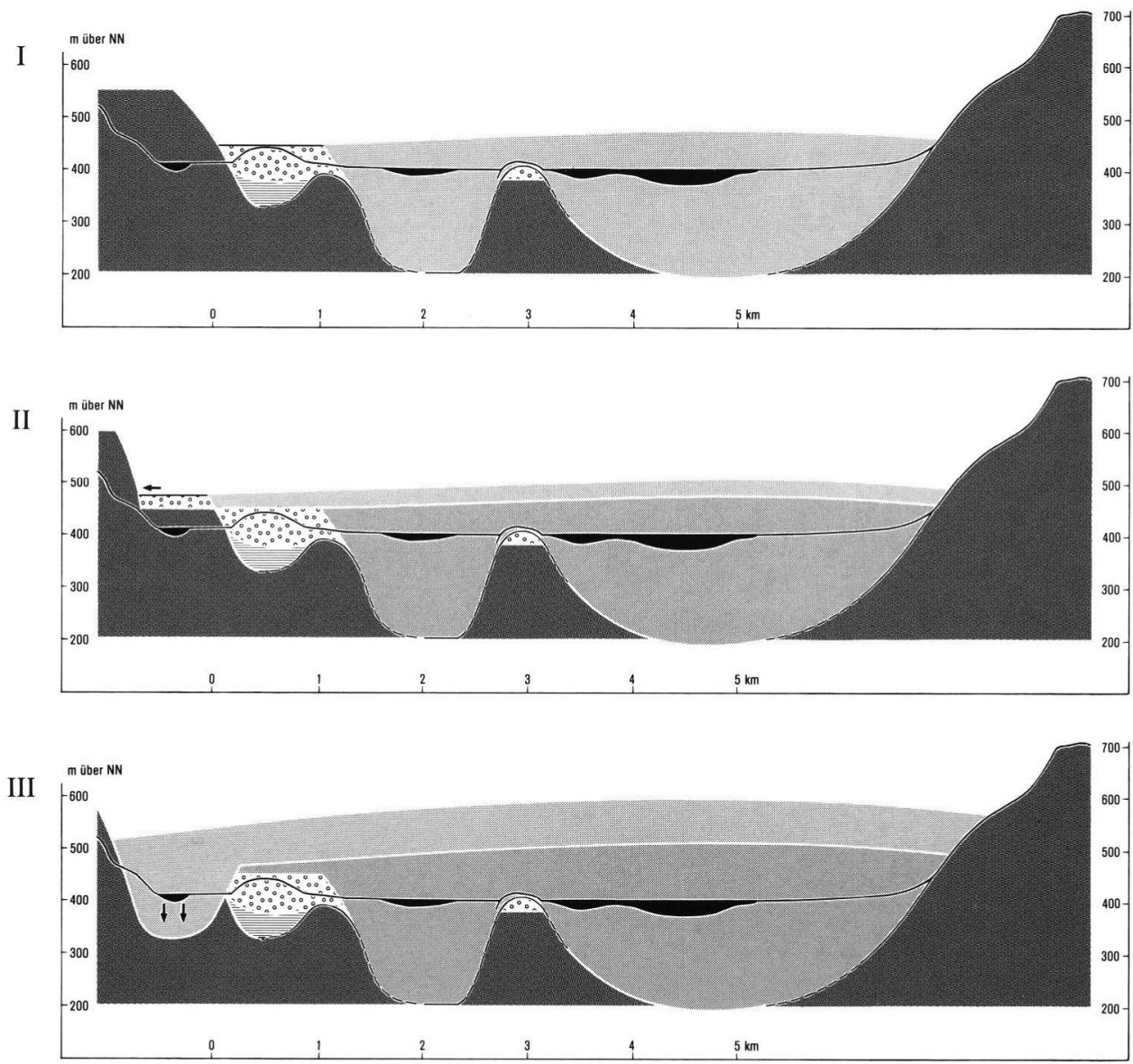

Anstehendes Gestein (Molasse)

Beckenfüllungen

Gletscher $\because \because \%$ Kameterrassen-Ablagerungen

$\downarrow \downarrow$ Tiefenerosion

Abb. 20: Querprofil über den zentralen Untersee und seine Flanken (nach Schreiner 1968, oben) und die Deutung des ebeneinanders von Kameterrassen und übertieften Rinnen (darunter). Zur Lage des Profils vgl. Abb. 19. Näheres im Text.

Fig. 20: Cross-section of the central Untersee basin and its flanks (after ScHreINER 1968, above) and the interpretation of the side-byside occurrence of kame-terraces and overdeepened channels (underneath). For location of the cross-section see fig. 19, for details see text. 
Mindestens die jeweils nördlich begrenzenden übertieften Rinnen müssen also später ausgeräumt worden sein. Weshalb aber sind dann die - ja gleichfalls vom Gletscher überfahrenen - Kiese von der Ausräumung ausgenommen worden?

Das Problem löst sich, wenn man einen vom Gletscherstand abhängigen mehrfachen Wechsel von Kameterrassen- und Becken-Bildung annimmt, wobei der rechte Beckenrand sukzessive zurückverlegt wurde. Der letzte Abschnitt der Entwicklung läßt sich relativ gut rekonstruieren. Wie er zu denken ist, ist in Abb. 20 (unten) dargestellt. Er verlief dreiphasig:

- zunächst (bei einem ersten Gletschervorstoß) Ablagerung der Markelfinger Kiese als Kameterrasse zwischen Gletscher und (damaligem) Beckenrand, nachfolgend Rück- und Niederschmelzphase, anschließend erneuter Gletschervorstoß;

- dann (bei nunmehr höherem Gletscherstand) vermutlich Bildung einer weiteren Kame-Terrasse in höherem Niveau, jedenfalls aber Rückverlegung und Versteilung des rechten Beckenrandes durch Seitenerosion, nachfolgend wiederum Rück- und Niederschmelzen und erneuter Vorstoß des Gletschers;

- schließlich (bei nochmals höherem Gletscherstand, und weil nun unter dem versteilten Beckenrand der Platz für eine weitere Kameterrasse fehlte) nur noch subglaziale Wasserbewegung und - mit wachsendem hydrostatischem Druck - rasche Eintiefung von Mindelsee-Becken und Güttinger Rinne. Die unmittelbar benachbarte Markelfinger Kameterrasse wurde dabei durch überlagerndes stagnierendes Eis der vorhergehenden Vorstöße vor der Abtragung geschützt.

Das Beispiel zeigt, daß die Kombination von Schutz des Untergrunds durch stagnierendes Eis eines vorhergehenden Vorstoßes und subglazialer Schmelzwassererosion nicht nur in der Längsrichtung eines Gletschervorstoßes (wie in Abb. 16 dargestellt), sondern auch quer dazu - im Verbund mit Seiten-/Tiefenerosion - wirksam werden konnte.

Eine solche Prozeßfolge muß sich - darauf weist die Mitwirkung von stagnierendem Eis hin - in relativ kurzer Zeit abgespielt haben, höchstwahrscheinlich während eines einzigen Großvorstoßes zu einer der seit Erb (1931, 1934) und SCHrEINER (1970) bekannten späthochglazialen Randlagen des würmzeitlichen Rheingletschers. Anhaltspunkte dafür liefern die Bohrungen längs der Güttinger Rinne (Abb. 21). Die Rinnenbasis läuft tief unter den Endmoränen des Standes 7 sensu SCHrEINER (1970) hindurch, die Rinne muß also älter sein. Andererseits können subglaziale Schmelzwässer normalerweise nur dort erosiv wirksam werden, wo sie das auflastende Eis anheben können. also nicht allzu weit von der Gletscher-

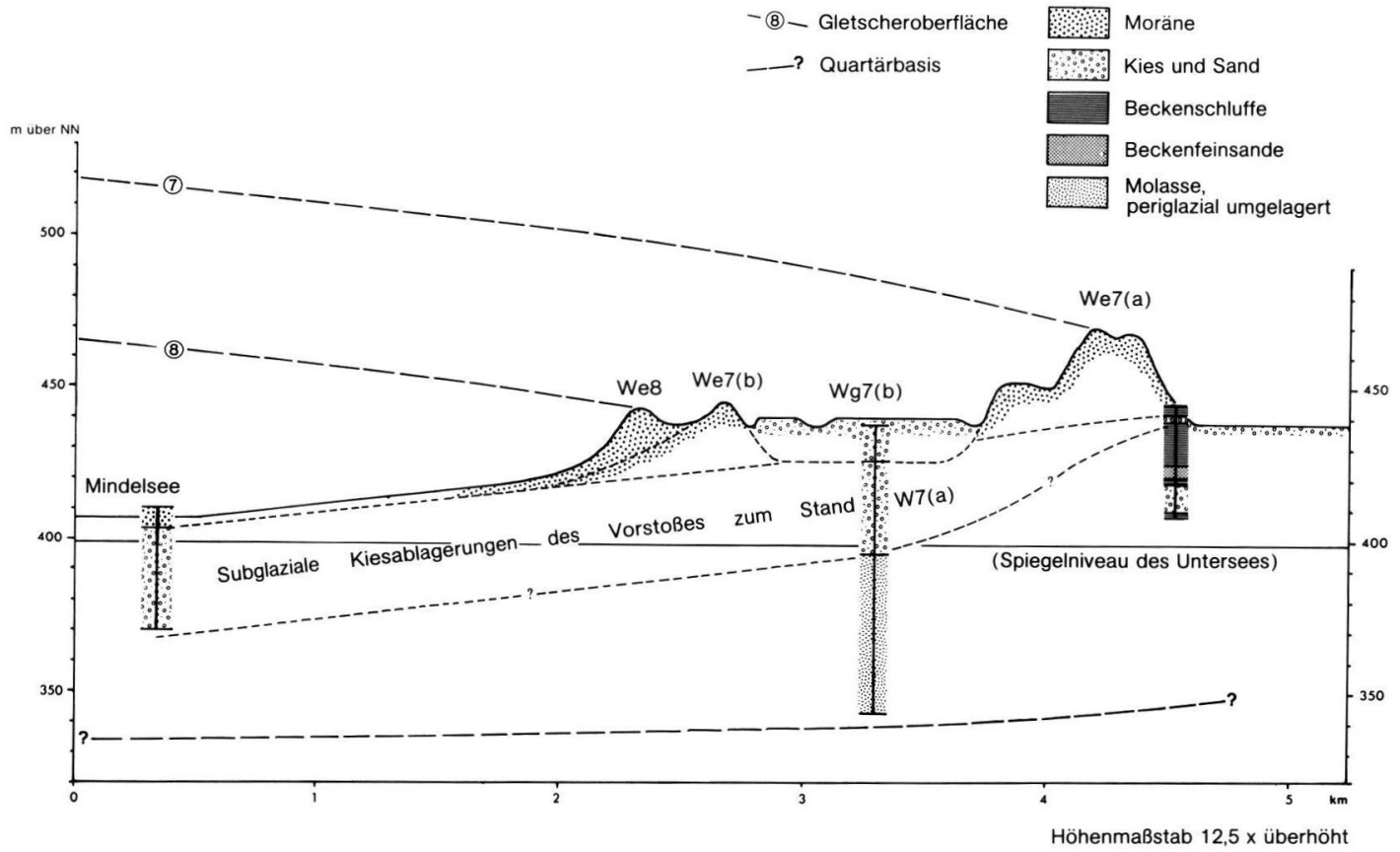

Abb. 21: Längsprofil durch den zentralen Teil des übertieften Talzugs Mindelseebecken-Güttinger Rinne. Bohrdaten nach SCHREINER (1968), Zuordnung der Gletscherstände nach Schreiner (1970, ergänzt). Zur Lage des Profils vgl. Abb. 19. Näheres im Text.

Fig. 21: Longitudinal profil of the central part of the overdeepened Mindelsee-Güttingen channel. Boring dates after SCHREINER (1968), assignment of the glacier stades after SCHREINER (1970, complemented). For location of the profile see fig. 19, for details see text. 
stirn. Das spricht dafür, daß die Güttinger Rinne (und zuvor die Kameterrassen-Ablagerungen der Markelfinger Kiese) zur Zeit der dem Stand 7 vorausgehenden nächstälteren Randlage des Rheingletschers, also von Stand 6 (des äußeren Standes der Inneren Jungendmoränen) entstand. Wenn das richtig ist, müßte sich die Güttinger Rinne unter den Wahlwieser Endmoränen (der Stände 7 und 8 des Überlinger See-Lobus des Gletschers) bis gegen Langenstein verfolgen lassen. Gewißheit darüber können nur neue Bohrungen bringen.

Die vorhandenen Bohrungen in (bzw. am Rande) der Güttinger Rinne liefern aber noch einen anderen Hinweis. Sie zeigen nämlich ein sowohl auf der Höhe des Mindelsees wie unter den Endmoränen des 7er Standes etwa 30 m mächtiges Kieslager, das vor der äußeren Moräne von Stand 7 - auf 1,60 m reduziert - zwischen Beckenschluffen darüber und darunter ausläuft. Nach den Lagerungsverhältnissen handelt es sich dabei mit großer Wahrscheinlichkeit um subglaziale Ablagerungen von Stand 7 (a). Da man außerdem die Gletscheroberfläche von Stand 7 (und 8) anhand der Ufermoränen am Südhang des Bodanrück recht zuverlässig rekonstruieren kann, läßt sich hier abschätzen, welche Beträge subglaziale Schmelzwassererosion schon unmittelbar hinter der Gletscherstirn im Verhältnis zum auflastenden Eis erreichen kann. Nimmt man die Oberkante der Beckenschluffe unter den oberen Kiesen vor der Stirn von Stand 7 (a) als Ausgangsniveau, die Basis der subglazialen Kiesablagerungen als Endniveau, ergibt sich ein Verhältnis von (maximal erreichter) Eishöhe über Ausgangsniveau zu Eintiefungsbetrag unter Ausgangsniveau von etwa 1:1. Dabei ist zu berücksichtigen, daß das ausgeräumte Material großenteils Lockermaterial, und daß der ausräumende subglaziale Schmelzwasserstrom kein Hauptschmelzwasserstrom des späthochglazialen Rheingletschers war (ein solcher Hauptschmelzwasserstrom verlief - worauf bereits [o. S. 114] hingewiesen wurde - während des ganzen späten Hochglazials unter dem Überlinger See-Ast des Gletschers).

Gleichwohl liefert das hier gegebene Verhältnis 1:1 zwischen Eismächtigkeit und Ausraum einen wichtigen Hinweis. Es zeigt nämlich, daß die großen Übertiefungsbeträge in den auslaufenden Alpentälern und im Alpenvorland, die hunderte von Metern erreichen können, mit der Vorstellung subglazialer Schmelzwassererosion in einem beschränkten Bereich hinter der Gletscherstirn allein nicht erklärt werden können. Wenn auch in diesen Fällen - wofür manches spricht - subglaziale Schmelzwassererosion das Hauptagens war, muß das auflastende Eis entsprechend mächtig gewesen sein, muß aber vor allem erklärt werden, wie unter einen so mächtigen Gletscher die großen Schmelzwassermengen geraten konnten, die für subglaziale Schmelzwasser- erosion unabdingbar sind. Es wäre denkbar, 1., daß für das Eindringen von Schneeschmelzwasser auch unter einen mächtigen Gletscher die gletscheraufwärts gelegenen Gefällsbrüche, und daß 2. für die Wasserwirksamkeit auch in großen Tiefen unter dem Gletscher von früheren Vorstößen herrührende wassererfüllte (und nicht zusedimentierte) Becken eine Rolle gespielt haben, in denen der vorstoßende Gletscher zunächst aufschwamm und dann - nach Erreichen des distalen Beckenrandes - das überdeckte Wasservolumen unter Druck und in Bewegung setzte und damit zur Erosion befähigte. Vergleichbare Vorstellungen hat PıотROwski (1994) für die Entwicklung der Tunneltäler Schleswig-Holsteins entwickelt. Ob sie auch für die $\mathrm{Al}$ pentäler und das Alpenvorland zu verifizieren sind, müssen weitere Untersuchungen zeigen.

\section{Schriftenverzeichnis}

BADER, K. (1979): Exarationstiefen würmzeitlicher und älterer Gletscher in Südbayern (Trennung eisvorbelasteter und nicht eisvorbelasteter Sedimente aufgrund der seismischen Geschwindigkeiten).- Eiszeitalter und Gegenwart 29: 49-61, 5. Abb; Hannover (DEUQUA)

CARol, H. (1943): Beobachtungen zur Entstehung der Rundhöcker. Die Alpen 19: 173-180.

- (1947): The formation of Roches moutonnées.- Journal of Glaciology 1: 57-59.

Church, M. (1972): Baffin Island sandurs - a study of arctic fluvial processes.- Geolog. Survey Canada Bullet. 216.

Cremaschi, M. (1987): Paleosols and vetusols in the central Po plain (Northern Italy) - A study in Quaternary geology and soil development.- Studi e ricerche sul territorio 28, 306 S., 106 Abb. 1 Karte; Milano (Unicopli).

Eu.lwanger, D. (1990): Würmzeitliche Drumlinformung bei Markelfingen (Westlicher Bodensee, Baden-Württemberg).- Jahresber. Mitteil. Oberrhein. Geolog. Verein 72: 411-434, 8 Abb. Stuttgart (Schweizerbarth).

Embleton, C. \& C. A. M. King (1975): Glacial Geomorphology. (2nd ed.), VI + 573 S., 137 Abb., 37 Taf.; London (Arnold).

ERB, L. (1931): Geologische Spezialkarte von Baden - Erläuterungen zu Blatt Hilzingen (Nr. 146).- 115 S.; Freiburg/Br.

(1934): Geologische Spezialkarte von Baden - Erläuterungen zu Blatt Überlingen (Nr. 148) und Blatt Reichenau (Nr. 161).$120 \mathrm{~S}$; Freiburg/Br.

FINSTERWALDER, R. (1931): Geschwindigkeitsmessungen an Gletschern mittels Photogrammetrie.- Zeitschr. f. Gletscherkunde 19: $251-262$.

- (1950): Some comments on glacier flow.- Journal of Glaciology 4: 383-388.

FischeR, K. (1994): Deutschlands Alpenanteil.- In: LiedTKE, H. \& J. Marcinek (Hg.): Physische Geographie Deutschlands: 477-501, 6 Abb.; Gotha (Perthes).

FLÜGEL, W. A. (1981): Hydrologische Studien zum Wasserhaushalt hocharktischer Einzugsgebiete im Bereich des Oobloyah-Tals, N-Ellesmere Island, N. W. T., Kanada.- In: D. BARSCH \& L. KING (Hg.): Ergebnisse der Heidelberg-Ellesmere Island-Expedition. Heidelberger Geogr. Arb. 69: 311-382.

Frank, H. (1979): Glazial übertiefte Täler im Bereich des Isar-Loisachgletschers - Neue Erkenntnisse über Aufbau und Mächtigkeit des Quartärs in den alpinen Tälern, im Gebiet des „Murnauer Schotters“ und im „Tölzer Lobus“ (Erste Mitteilung).- Eiszeitalter u. Gegenwart 29: 77-99, 8 Abb., 1 Tab., 2 Taf.; Hannover (DEUQUA).

HaвBE, K.A. (1969): Die würmzeitliche Vergletscherung des Gardasee-Gebietes - Studien über Verbreitung und Formenschatz der jungquartären Ablagerungen am Alpensüdrand zwischen 
Chiese und Etsch.- Freiburger Geograph. Arb. 3, 254 S., 4 Abb., 11 Beil.; Freiburg/Br. (Schulz).

- (1985): Das Späthochglazial der Würm-Eiszeit im Illergletscher-Gebiet - Ergebnisse einer geomorphologischen Kartierung.- Quartär 35/36: 55-68, 8 Abb.; Bonn (Röhrscheid).

- (1988): Zur Genese der Drumlins im süddeutschen Alpenvorland - Bildungsräume, Bildungszeiten, Bildungsbedingungen.Zeitschr. f. Geomorphologie N. F. Suppl.-Bd. 70: 33-50, 11 Abb.; Berlin/Stuttgart (Borntraeger).

- (1995): Zur Diskussion über die Chronostratigraphie des Pleistozäns im Alpenvorland und zu einigen daraus resultierenden Schlußfolgerungen für die Geomorphologie.- Regensburger Geograph. Schriften 25: 49-63, 4 Abb.; Regensburg (Institut für Geographie).

Haeberli, W. \& U. Penz (1985): An attempt to reconstruct glaciologi$\mathrm{cal}$ and climatological characteristics of $18 \mathrm{ka}$ BP ice age glaciers in and around the Swiss Alps.- Zeitschr. f. Gletscherkunde u. Glazialgeologie 21: 351-361, 4 Abb., 2 Tab.; Innsbruck (Wagner)

HAEBERLI, W. \& Chr. SChLÜCHTER (1987): Geological evidence to constrain modelling of the Late Pleistocene Rhonegletscher (Switzerland).- In: The Physical Basis of Ice Sheet Modelling - Proceedings of the Vancouver Symposium, August 1987. IAHS Publ. no. 170: 333-346, 6 Abb., 1 Tab.

HeIm, A. (1885): Handbuch der Gletscherkunde.- Stuttgart (Engelhorn).

- (1919-22): Geologie der Schweiz.- 2 Bde. Leipzig (Tauchnitz).

VAN Husen, D. (1987): Die Ostalpen in den Eiszeiten.- 24 S., 23 Abb.; Wien (Geolog. Bundesanstalt).

KfLler, O. (1994): Entstehung und Entwicklung des Bodensees - Ein geologischer Lebenslauf.- In: MAURER, H. (Hg.): Umweltwandel am Bodensee: 32-92, 24 Abb.; St. Gallen (UVK).

Krayss, E. \& O. Keller (1983): Die Bodensee-Vorlandvereisung während des Würm-Hochglazials.- Schriften d. Vereins f. Geschichte des Bodensees 101: 113-129, 6 Abb.; Friedrichshafen (Verein für Geschichte des Bodensees).

Louis, H. (1952): Zur Theorie der Gletschererosion in Tälern.- Eiszeitalter und Gegenwart 2: 12-24, 3 Abb.; Öhringen (Rau).

- unter Mitarbeit von K. FISCHER (1979): Allgemeine Geomorphologie.- Lehrbuch der Allgemeinen Geographie, Bd. 1 (4. Aufl.), XXXI + 814 S., 146 Abb., 2 Beil., 174 Bilder in ges. Bilderteil; Berlin (de Gruyter).

Marcinek, J. (1985): Gletscher der Erde.- 214 S., 113 Abb., 15 Bilder auf Tafeln; Thun/Frankfurt (Deutsch).

McCann, S. B., P. J. Howarth \& J. G. Cogley (1972): Fluvial processes in a periglacial environment - Queen Elizabeth Islands, N.W.T., Canada.- Inst. Brit. Geograph. Transactions 55: 69-92.

Menzies, J. (ed.) (1995-96): Glacial Environments - Processes, Sediments and Landforms - vol. I: Modern Glacial Environments Processes, Dynamics and Sediments, vol. II: Past Glacial Environments - Sediments, Forms and Techniques.- XXVI + 621/XXIV + 598 S.; Oxford (Butterworth/Heinemann).
NORDDAHL, H. (ed.): Abstracts - INQUA Commission on Formation and Properties of Glacial Deposits - Meeting in Iceland, August 1994: Deckblatt.

Paterson, W. S. B. (1969): The physics of glaciers.- VIII + 250 S., 46 Abb., 9 Tab.; Oxford/New York (Pergamon). 3rd ed. 1994.

PencK, A. (1899): Die Übertiefung der Alpentäler.- Verh. VII. Internation. Geographen-Kongr., Bd. II: 232-240. Berlin (Kühl).

- (1912): Schliffkehle und Taltrog.- Petermanns Geograph. Mitteil. 58 (II. Halbband): 125-127.

- \& E. Brückner (1901-09): Die Alpen im Eiszeitalter.- 3 Bde., 1199 S., 138 Abb., 38 Taf., 19 Karten; Leipzig (Tauchnitz).

Philippson, A. (1912): Der glaziale Taltrog.- Petermanns Geograph. Mitteil. 58 (II. Halbband): 277.

PIOTROwSKI, J. A. (1994): Tunnel-valley formation in northwest Germany - geology, mechanisms of formation and subglacial bed conditions for the Bornhöved tunnel valley.- Sedimentary Geology 89: 107-141, 17 Abb.; Amsterdam (Elsevier).

SCHREINER, A. (1968): Eiszeitliche Rinnen und Becken und deren Füllung im Hegau und westlichen Bodenseegebiet.- Jahreshefte Geolog. Landesamt Baden-Württemberg 10: 79-104, 3 Abb.; Freiburg/Br. (Herder).

- (1970): Erläuterungen zur Geologischen Karte des Landkreises Konstanz mit Umgebung 1:50.000.- 286 S., 28 Abb., 11 Taf., 5 Beil.; Stuttgart (Landesvermessungsamt Baden-Württemberg).

- (1973): Geologische Karte von Baden-Württemberg 1:25.000 Erläuterungen zu Blatt 8219 Singen.- 130 S., 12 Abb., 4 Taf., 6 Beil.; Stuttgart (Landesvermessungsamt Baden-Württemberg).

- (1979): Zur Entstehung des Bodenseebeckens.- Eiszeitalter u. Gegenwart 29: 71-76, 4 Abb.; Hannover (DEUQUA).

SCHUNKE, E. (1981): Abfluß und Sedimenttransport im periglazialen Milieu Zentral-Islands als Faktoren der Talformung.- Die Erde 112: 197-215, 10 Abb.; Berlin (Gesellschaft für Erdkunde).

- (1989): Schneeschmelzabfluß, Aufeis und fluviale Morphodynamik in periglazialen Flußgebieten NW-Kanadas.- Erdkunde 43: 268-280, 6 Abb., 6 Photos; Bonn (Dümmler).

SCHWARzBACH, M. (1964): Geologische Tätigkeit des Eises und die Periglazialgebiete.- In: Brinkmann, R. (Hg.): Lehrbuch der Allgemeinen Geologie, Bd. 1: 207-249; Stuttgart (Enke).

Sugden, D. E. \& B. S. John (1976): Glaciers and Landscape - A Geomorphological Approach.- VIII + 376 S., 238 Abb.; London (Arnold).

WeBER, H. (1967): Die Oberflächenformen des festen Landes Einführung in die Grundzüge der allgemeinen Geomorphologie.- (2. Aufl.), 367 S., 244 Abb., 106 Bilder; Leipzig (Teubner).

Wilhelmy, H. (1992): Geomorphologie in Stichworten.- (5. Aufl.), Bd. III: Exogene Morphodynamik, neubearb. v. H. Fischer u. Chr. Embleton-Hamann; 176 S., 47 Abb.; Berlin/Stuttgart (Hirt).

Manuskript eingegangen am 06.02.1995 